\title{
Comprehensive genomic and immunophenotypic analysis of CD4 T cell infiltrating human triple-negative breast cancer
}

\author{
He Zhang ${ }^{1} \cdot$ Guohui Qin ${ }^{2} \cdot$ Hui Yu$^{3} \cdot$ Xu Han $^{1} \cdot$ Sha Zhu ${ }^{1}$ (I)
}

Received: 20 August 2020 / Accepted: 21 November 2020 / Published online: 10 December 2020

(c) The Author(s) 2020

\begin{abstract}
The aim of this study is to investigate the gene expression module of tumor-infiltrating $\mathrm{CD} 4^{+} \mathrm{T}$ cells and its potential roles in modulating immune cell functions in triple-negative breast cancer. Differentially expressed genes were identified by comparison of the expression profile in $\mathrm{CD} 4^{+} \mathrm{T}$ cells isolated from tumor tissues and peripheral blood of TNBC patients respectively. The differential expression analysis was conducted using $\mathrm{R}$, and then the functional and pathway enrichment of the DEGs were analyzed using GSEA, followed by integrated regulatory network construction and genetic analysis of tumor-infiltrating immune cells based on a scientific deconvolution algorithm. As a result, abundant Treg and exhausted lymphocytes were detected, accompanied by largely decreased of effector/memory and cytotoxic $\mathrm{T}$ cells. Immune-related gene correlation analysis showed that the extent of follicular helper $\mathrm{T}$ cells gene expression signatures were inversely associated with those of $\mathrm{CD}^{+}$naive $\mathrm{T}$ cells and $\mathrm{CD} 4^{+}$memory resting $\mathrm{T}$ cells, but positively correlated with that of $\mathrm{CD} 4^{+}$memory activated T cells. In addition, we found five core genes including IFNG, CTLA4, FAS, CXCR6, and JUN were significantly over expressed in $\mathrm{CD}^{+}$TILs which may contribute to exhaustion of lymphocytes and participate in biological processes associated with regulation of chemotaxis. Study provides a comprehensive understanding of the roles of DEGs associated with the chemotactic and exhausted immunophenotypes of $\mathrm{CD}^{+}$TILs that are a valuable resource from which future investigation may be carried out to better understand the mechanisms that promote TNBC progression.
\end{abstract}

Keywords $\mathrm{CD}^{+}{ }^{+} \mathrm{T}$ cell $\cdot$ Tils $\cdot$ Gene expression profile $\cdot$ Exhaustion $\cdot$ Chemotaxis $\cdot$ Degs

\section{Introduction}

Breast cancer is a prevalent malignancy in female globally, with $\sim 1.4$ million new cases diagnosed annually [1], of which triple-negative breast cancer (TNBC) represents

Supplementary Information The online version contains supplementary material available at https://doi.org/10.1007/s0026 2-020-02807-1.

Sha Zhu

zsha@zzu.edu.cn

1 Key Laboratory of Tumor Immunity, Center of Infection and Immunization, Department of Immunology, School of Basic Medical Sciences, Cancer Hospital Affiliated To Zhengzhou University, Zhengzhou University, Zhengzhou 450001, People's Republic of China

2 Biotherapy Center, First Affiliated Hospital of Zhengzhou University, Zhengzhou 450052, People's Republic of China

3 Henan Animal Health Supervision Institute, Zhengzhou 450008, People's Republic of China approximately $15-20 \%$ and have the highest genomic instability rates when compared with other breast cancer subtypes [2]. Previous studies have shown that TNBC can stimulate the immune system to form a tumor microenvironment (TME) where immune cells are the main component which can be identified as potential prognostic factors for TNBC patients [3]. Tumor-infiltrating lymphocytes (TILs) play an important role in promoting host protection against cancer and facilitating tumor escape from immune destruction [4, 5]. The intensity of tumoral immune response influences the effectiveness of cancer therapy and is also correlated with favorable clinical outcome of the patients [6].

Most neoantigens of cancer cells can stimulate $T$ cells and also induce a regulatory immune response $[7,8]$. Intratumoral $\mathrm{CD} 4{ }^{+} \mathrm{T}$ cells are increasingly recognized as responsible for antitumor immune response and the production of inflammatory mediators that induce tumor growth, invasion, angiogenesis, and metastasis which are associated with clinical outcomes $[9,10]$. Study reported that increasing numbers of $\mathrm{CD} 4^{+} \mathrm{T}$ cells correlated significantly with improved 
disease-specific survival and that a high density of stromal $\mathrm{CD} 4^{+} \mathrm{T}$ cells was a favorable independent prognostic factor in non-small cell lung cancer (NSCLC) patients [11]. Accumulating evidence confirmed the prognostic value of $\mathrm{CD} 4^{+}$ $\mathrm{T}$ cells for many other tumors [12-15] and it has been documented that high intensity of intratumoral $\mathrm{CD} 4^{+} \mathrm{T}$ cell is associated with a better outcomes $[15,16]$.

The expression profiles of the intratumoral $\mathrm{CD} 4^{+} \mathrm{T}$ cells can be used to analyze tumor-infiltrating $\mathrm{T}$ cell subsets and to predict how a patient will respond to cancer therapy [17]. A comprehensive understanding of the intratumoral $\mathrm{T}$ cell characteristics contributes to early diagnosis and precise treatment [18]. Study has shown that an increased proportion of TILs, such as $\mathrm{CD} 4^{+} \mathrm{T}$ and $\mathrm{CD} 8^{+} \mathrm{T}$ cells, was associated with better clinical outcomes in breast cancer [19]. It has been proposed that the characterization of TILs, like their immunophenotype, could help screen immunotherapy clinical trials [20]. Numerous studies have demonstrated that tumor immunotherapy, in particular, activation of intratumoral helper $\mathrm{T}$ cells, is an alternative or complement to chemotherapy or surgery [21-23]. Study indicated that blockade of the immune checkpoint protein cytotoxic T-lymphocyte-associated protein 4 (CTLA4) enhance the antitumor immune responses ability of the immune cells in TME [24]. With the effective clinical usage of immunetargeted therapies, a key issue is to identify the biological and genetic factors of intratumoral lymphocytes involved in the immune response.

On that basis, the aim of this study was to investigate the gene expression profile of tumor-infiltrating $\mathrm{CD}^{+} \mathrm{T}$ cells and to predict their potential roles in modulating antitumor immune function. In this work, we use microarray data to analyze the phenotype and gene expression characteristics of tumor-infiltrating $\mathrm{CD}^{+} \mathrm{T}$ cells from TNBC patients. This study might provide clues for better understanding the phenotype of these cells in particular attenuation of immune suppression which may offer clinical benefit for controlling and suppressing tumor progression.

\section{Subjects and methods}

\section{Patients and samples}

All human samples used in the experiments were tested in accordance with the ethical principles of Zhengzhou University. Patients with TNBC who had not received chemotherapy or radiotherapy were included in the present study such as microarray, quantitative real-time PCR, immunohistochemical, and immunofluorescence evaluation (Table 1). $\mathrm{CD} 4^{+} \mathrm{T}$ cells isolated from primary tumor tissues were compared by microarray and RT-qPCR with the cells from peripheral blood $(\mathrm{PB})$ of the TNBC patients respectively. All patients agreed
Fig. 1 Microarray analysis for screening the DEGs in isolated $\mathrm{CD}^{+}$ $\mathrm{T}$ cells. Detection of $\mathrm{CD}^{+} \mathrm{T}$ cells by immunohistochemistry in representative $\mathrm{TNBC}$ samples a $\mathrm{CD} 4^{+} \mathrm{T}$ cells in stroma, b $\mathrm{CD} 4^{+}$ $\mathrm{T}$ cells in stroma and infiltrated among the cancer cells. Flow cytometric analysis was performed immediately after $\mathrm{CD} 4{ }^{+} \mathrm{T}$ cells isolated from PB $\mathbf{c}$ or TNBC tissues d. e Volcano plots of DEGs from analyzed microarray data. $\mathbf{f}$ The dendrogram of DEGs in the $\mathrm{CD}^{+}$ $\mathrm{T}$ cells. Red represents higher expression and green lower expression. The criteria used to select DEGs were $P<0.05$ and $\mid \operatorname{logFCl}>1$. DEGs, differentially expressed genes

with their surgical or biopsy specimens to be used in research. $\mathrm{CD} 4^{+} \mathrm{T}$ cells were positively purified by microbeads (Miltenyi Biotec, Germany) and AutoMACS (Miltenyi Biotec). All the processes were carried out according to the manufacturers' instructions. Flow cytometry was used to control the cell purification with the purity of negatively samples $>98 \%$, and the purity of positive TILs samples was $>95 \%$.

\section{Microarrays and DEG identification}

The isolated $\mathrm{CD}^{+}{ }^{+} \mathrm{T}$ cells from tumors and $\mathrm{PB}$ were used for affymetrix microarray. Total RNA from $\mathrm{CD} 4^{+} \mathrm{T}$ cells used for microarray was extracted using an RNeasy Mini kit (Qiagen, Valencia, CA). Amounts, purity, and integrity of RNA were assessed on a spectrophotometer (NanoDrop, Nyxor Biotech). High-quality total RNA was labeled following the manufacturer's protocols for probe preparation and hybridization on the Affymetrix U133 Plus 2.0 GeneChip. Affypackage in $\mathrm{R}$ was used to normalize and convert CEL files to expression data [25, 26]. The differentially expressed genes (DEGs) were subsequently calculated using the Limma package, based on the false discovery rate controlling procedures [27]. $\mid \log \mathrm{FCl}>1$ and $P<0.05$ were used as comparison criteria and threshold to

Table 1 Demographics and characteristics of the study group $(\mathrm{n}=$ 61)

\begin{tabular}{ll}
\hline Variable & $\begin{array}{l}\text { Number or } \\
\text { character- } \\
\text { istics }\end{array}$ \\
\hline $\begin{array}{l}\text { Mean age at diagnosis } \\
\text { Median age at diagnosis }\end{array}$ & 54.3 \\
Standard deviation & 55 \\
T-stage & 9.14 \\
II & \\
III & 35 \\
N-stage & 36 \\
ER status & Positive \\
PR status & Negative \\
HER2 status & Negative \\
Neoadjuvant chemotherapy & Negative \\
\hline
\end{tabular}


a

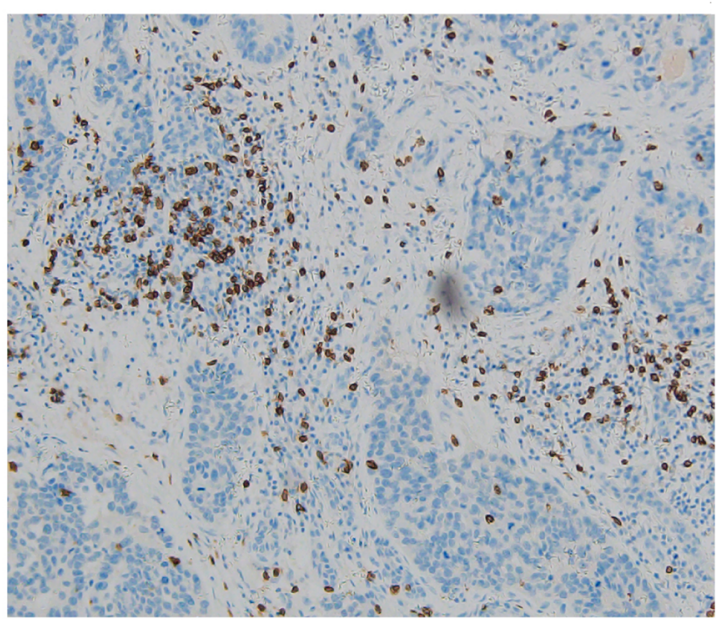

c

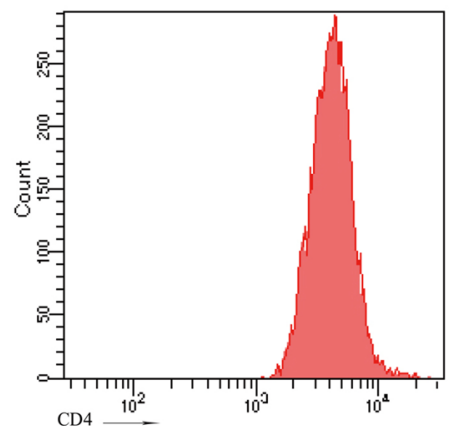

f

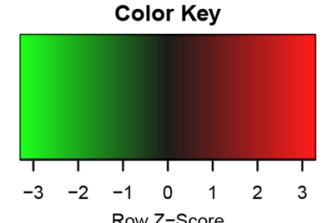

d b
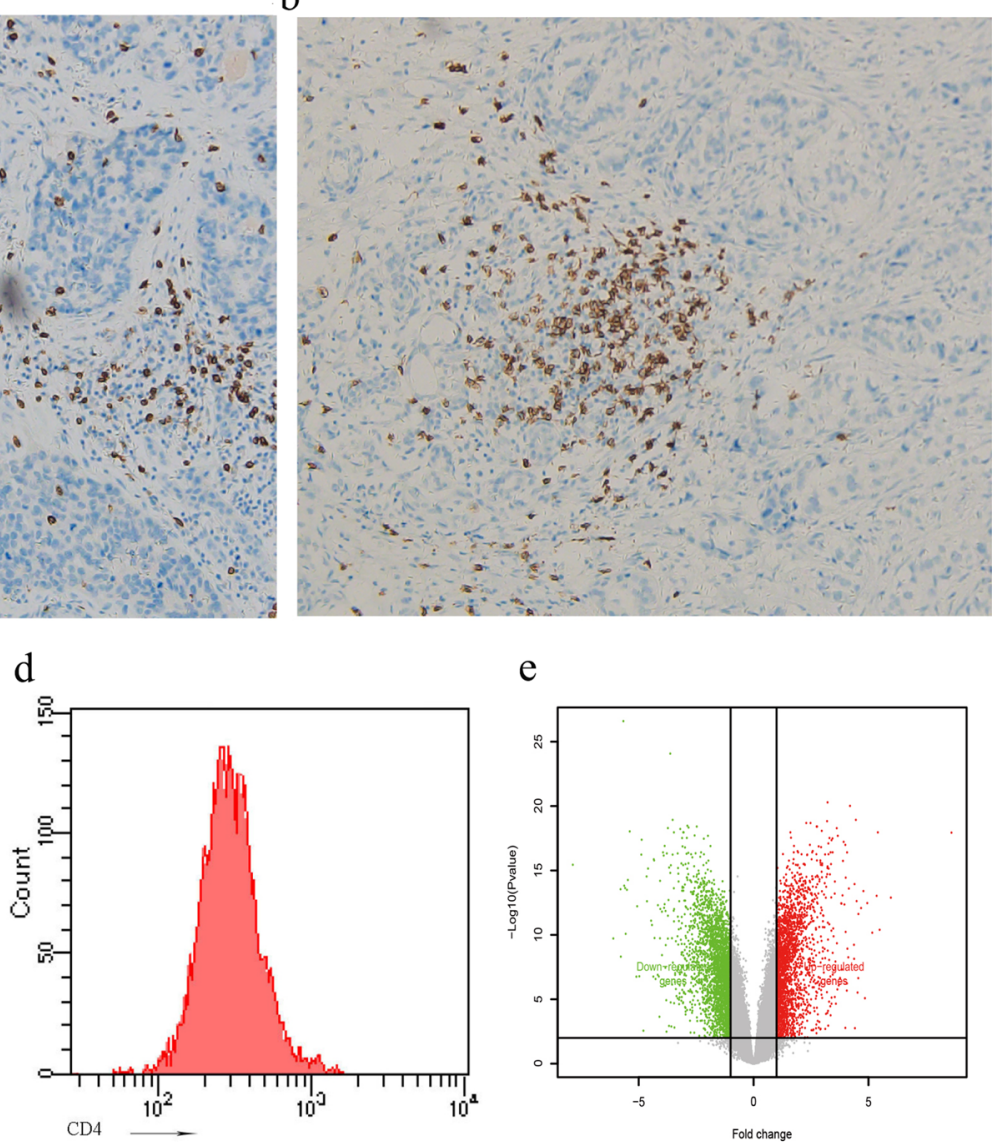

e

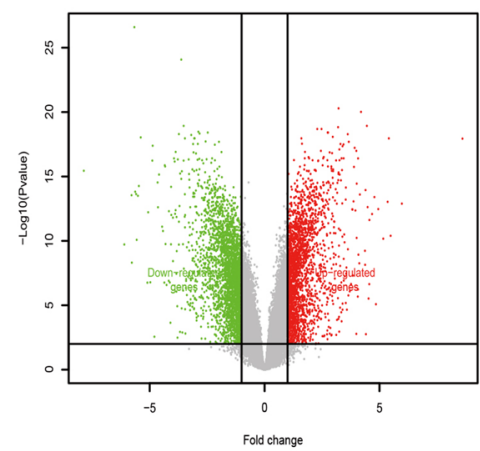

Heatmap

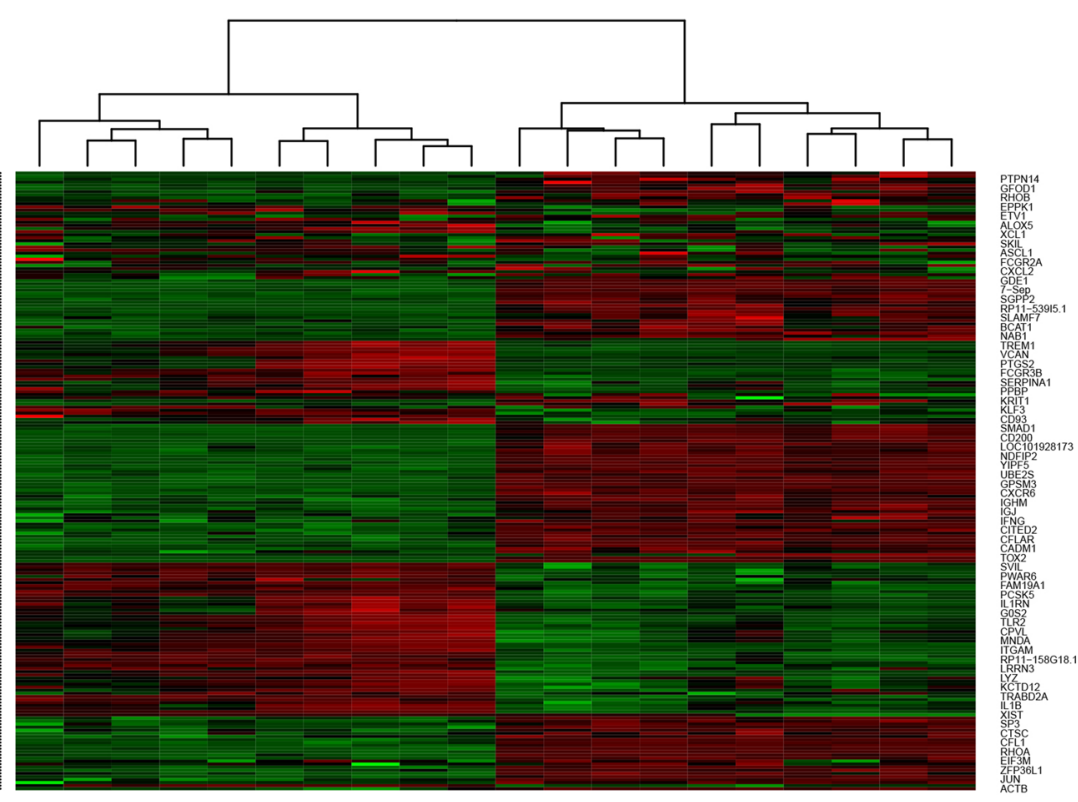

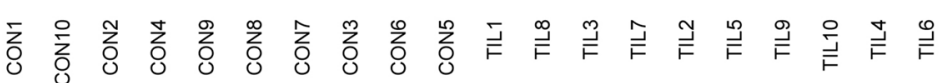


define the differentially expressed genes for $\mathrm{CD} 4^{+} \mathrm{T}$ cells between TNBC and PB samples.

\section{Functional and pathway enrichment analysis}

Gene Ontology (GO) enrichment analysis was performed using Database for Annotation, Visualization and Integrated Discovery (DAVID) [28]. The DEGs in the tumor-infiltrating $\mathrm{CD}^{+} \mathrm{T}$ cells of breast cancer patients were screened for functional enrichment. The potential functions of the DEGs in biological processes, molecular functions and cellular components were predicted by GO analysis. In addition, systematic analysis of differences in gene functions was conducted using the Kyoto Encyclopedia of Genes and Genomes (KEGG) database [29]. GO functional and KEGG pathway enrichment analyses were performed for the upregulated and down-regulated genes, respectively. The terms with $P$-value $<0.05$ and count $\geq 2$ were considered the cutoff criterion.

\section{GSEA analysis of the DEGs}

Gene Set Enrichment Analysis (GSEA) analysis [30] based on predefined gene sets from the Molecular Signatures Database (MSigDB v5.0, http://software.broadinstitute.org/gsea/ msigdb/index.jsp) was used to assesses whether an a priori defined set of genes shows statistically significant, concordant differences between two biological states. A gene set is a group of genes that shares pathways, functions, chromosomal localization, or other features. For the present study, we used "C7. all. V7.2 symbols. gmt" collection sets for GSEA analysis and list of ranked genes based on a score calculated as $-\log 10$ of $P$-value multiplied by the sign of fold-change. The number of permutation is set to 1000 .

\section{Evaluation of TILs}

The analytical tool CIBERSORT (Cell-type Identification By Estimating Relative Subsets Of RNA Transcripts) was used to determine relative proportions of immune cells through deconvolute mixed samples [17]. The CIBERSORT is a deconvolution algorithm, based on 22 immune cell reference profiles, which uses a "signature matrix" of genes' expression values to characterize immune cell composition [31]. In other words, the 22 cell subpopulations of the tumor microenvironment were evaluated using the CIBERSORT to analyze the normalized gene expression values. The immune subpopulations from TILs and PB were assessed employing two different unsupervised approaches: the hierarchical clustering method and PCA (R-bioconductor, statspackage) which performed using the ComplexHeatmap package within R-bioconductor. The samples with $P<0.05$ were included.

\section{PPI network and module analyses}

STRING (version 10.0, http://www.stringdb.org/) is an online database retrieving gene interactions to provide experimental and predictive PPI (protein-protein interaction) information [32]. Cytoscape software (version 3.2.0, http://www.cytoscape.org) was used to construct PPI networks [33] to visualize the interaction of the up-regulated and down-regulated genes [34]. Subsequently, the degree centrality of the nodes was calculated by the CytoHubba plug-in [35] software. The hub proteins were identified with higher degrees of centrality [36]. Additionally, the KEGG pathway enrichment analysis for nodes in the significant modules was performed using MATHT tool.

\section{Gene validation using RT- qPCR}

We selected patients who were confirmed diagnostic of triple-negative breast cancer. Total RNA from $\mathrm{CD} 4{ }^{+} \mathrm{T}$ cells was extracted by Trizol reagent (Takara, Dalian, China). Conversion of the mRNA to cDNA was performed using a Taqman Reverse Transcription kit (Roche, Branchburg, $\mathrm{NJ}$ ) according to the manufacturer's instructions. Real-time quantitative PCR was performed using QPK-201 SYBR Green master mix (Toyobo, Osaka, Japan) and the ABI 7300 system from Applied Biosystems. The thermocycling protocol was set as an RT step at $50{ }^{\circ} \mathrm{C}$ for $20 \mathrm{~min}$, DNA polymerase activation step at $95^{\circ} \mathrm{C}$ for $2 \mathrm{~min}$ and total 35 PCR cycles $\left(95^{\circ} \mathrm{C}\right.$ for $20 \mathrm{~s}, 60^{\circ} \mathrm{C}$ for $\left.30 \mathrm{~s}\right)$ [29]. The primers used in this study were synthesized from Invitrogen (Beijing China). All reactions were performed in triplicate. Comparative CT method was used to calculate the fold change of expression in each gene. Expression data are described by a log-ratio calculated by comparing $\Delta \mathrm{Cq}$ from the tumorinfiltrating $\mathrm{CD}^{+} \mathrm{T}$ cells with $\Delta \mathrm{Cq}$ from the controls.

\section{Algorithmic evaluation of the immune cells by ImmuCellAI}

Immune Cell Abundance Identifier (ImmuCellAI), a gene set signature-based method, was designed to estimate the abundance of the immune subsets from gene expression data. For maintaining the correlative structure of real data and controlling the mixing ratios of immune cell components, the 
gene-gene covariance matrix was calculated for all genes in using gene expression data. Subsequently, immune cell subsets were randomly sampled from uniform and length $n$ was calculated, which was the average of gene expression in the reference profiles of the immune cell types. Next, a vector of length $n$ was sampled from the multivariate normal distribution with mean length and covariance. For screening marker genes, the average correlation between gene expression data in tumor-infiltrating $\mathrm{CD} 4^{+} \mathrm{T}$ cells from TNBC patients and control samples was calculated using the Pearson correlation for all samples. Next, for each marker gene per immune cell, the standard correlation deviation among the cell with other cells was calculated, and genes with standard deviation larger than 1.5 were selected.

\section{Immunohistochemical and immunofluorescence evaluation}

Immunohistochemistry (IHC) was conducted using sections $(4 \mu \mathrm{m})$ of formalin-fixed, paraffin-embedded tumor tissues from patients with triple-negative breast cancer. Following deparaffinization and rehydration of the tissue sections, antigen retrieval was performed by microwaving in $10 \mathrm{mM}$ citrate buffer ( $\mathrm{pH}$ 6.0). After blockade of endogenous peroxidase, mouse anti-CTLA4, CXCR6, and FAS primary monoclonal antibodies (Agilent Technologies) and peroxidase-conjugated, rabbit anti-mouse secondary antibody (Agilent Technologies) were sequentially applied at 1:50 and 1:500 dilution respectively. The sections were visualized by diaminobenzidine (DAB) and counterstained with hematoxylin. For immunofluorescence staining, after deparaffinizing, rehydrating, antigen retrieval and endogenous peroxidase activity blocking, Cy3 or FITC (BioLegend, USA) was used as a secondary antibody $(1.5 \mu \mathrm{g} / \mathrm{mL})$ for one hour, and nuclei were counterstained by 4'-6-diamidino-2-phenylindole (DAPI; Sigma, USA) for $10 \mathrm{~min}$ [37]. In TUNEL assay, TDT enzyme, dUTP and buffer from the TUNEL kit were mixed at a ratio of 1:5:50. The reaction solution was added on the tissue placed in a flat wet box. Finally, after dehydration and mounting, the tissue sections were observed under a microscope (Olympus BX51, JP) at a magnification of $200 \times$. At least six sections of one tumor tissue were used for quantitative evaluation.

\section{Statistics}

Two-tailed Student's $t$ test with unequal variance (or a $\chi^{2}$ test) was used to calculate the $P$ values for the experimental data. $P<0.05$ was considered significant. Data are shown as the mean \pm SD.

\section{Results}

\section{Gene Expression Profile of CD4 ${ }^{+}$TILs in TNBC}

The distribution of CD4 ${ }^{+}$TILs were detected by IHC in samples of TNBC and normal breast tissue, as shown in Fig. 1a, b and Supplementary Fig. 1a a large number of $\mathrm{CD}^{+}{ }^{+} \mathrm{T}$ cells were frequently distributed in stromal compartments within tumor borders, while some of the cells scattered within tumors area. In addition, The proportion of $\mathrm{CD}^{+} \mathrm{T}$ cells in normal and tumor tissue were quantitatively analyzed and showed in Supplementary Fig. 1b-d. We purified CD4 ${ }^{+}$TILs from 10 TNBC patients who were previously treatment-naive for microarray. After purification, mean purities for $\mathrm{CD}^{+}{ }^{+} \mathrm{T}$ cells from tumors and $\mathrm{PB}$ were $99.4 \%$ (98.3-99.7\%) and 99.1\% (97.6-99.5\%) respectively (Fig. 1c, d). To identify differentially expressed genes (DEGs) between $\mathrm{CD}^{+}{ }^{+} \mathrm{T}$ cells from $\mathrm{TNBC}$ and from $\mathrm{PB}$, threshold $\log \mathrm{FCl}>1$ and $P<0.05$ was used as criteria for comparison. Results showed that a total of 2968 DEGs were identified and among them, 1431 were down-regulated and 1537 were up-regulated (Fig. 1e). The dendrogram of top DEGs in CD4 ${ }^{+} \mathrm{T}$ cells was shown in Fig. 1f.

\section{Functional annotation and pathway enrichment of DEGs}

Gene Ontology (GO) and Kyoto Encyclopedia of Genes and Genomes (KEGG) pathway analysis were performed to explore the unique role of candidate genes. The top ten biological process terms were mainly involved in the regulation of lymphocyte and leukocyte activation, cell cycle phase, and mitotic cell cycle (Fig. 2a). With regard to the cellular components, the DEGs were primarily associated with cell surface, spindle, and intracellular non-membranebounded organelle (Fig. 2b). In terms of molecular function, it indicated that the DEGs were mostly enriched in cytokine binding, transcription regulator activity, and protein dimerization activity (Fig. 2c). Followed KEGG pathway enrichment analysis showed that the DEGs were basically enriched in Jak - STAT signaling pathway, cytokine-cytokine receptor interaction, and chemokine signaling pathway (Fig. 2d). The top 5 enriched terms are presented in Table 2. It is showed that the differentially expressed genes are mainly involved in lymphocytes activation and mitosis the in biological process (Table 2). Results revealed the proteins of IFNG, CXCR6, and CD80 shared the same critical pathways like regulation of lymphocyte adhesion, whereas CTLA4 and FAS participated in negative regulation of lymphocyte exhaustion and programmed 
Fig. 2 GO, KEGG and GSEA analyses of DEGs. a-c GO analyses. Shown are the top 10 biological processes a, cellular components $\mathbf{b}$, and molecular functions c. d KEGG pathway analysis. e Enrichment of genes in DP_THYMOCYTE_VS_NAIVE_CD4_T CELL_ADULT_BLOOD_UP by GSEA. f Enrichment of genes in DOUBLE_POSITIVE_VS_CD4_SINGLE_ POSITIVE_THYMOCYTE_ DN by GSEA. $\mathrm{g}$ Enrichment of genes in MEMORY_CD4_ TCELL_VS_TH1_UP by GSEA. $\mathbf{h}$ Enrichment of genes in RESTING_VS_TCR_ACTIVATED_CD4_TCELL_UP by GSEA. The GSEA software was used to calculate the enrichment levels a

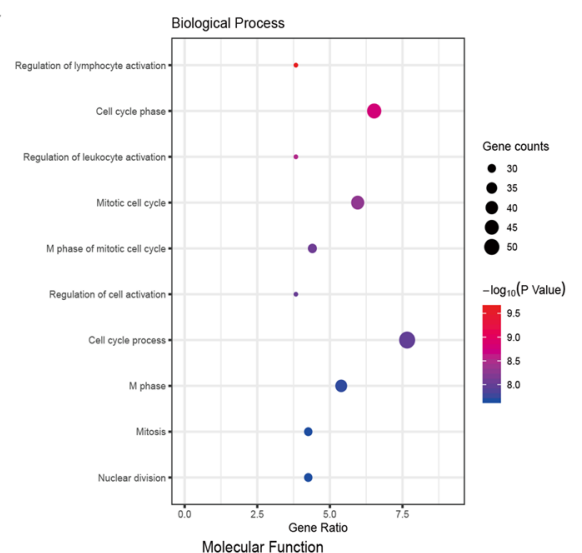

c

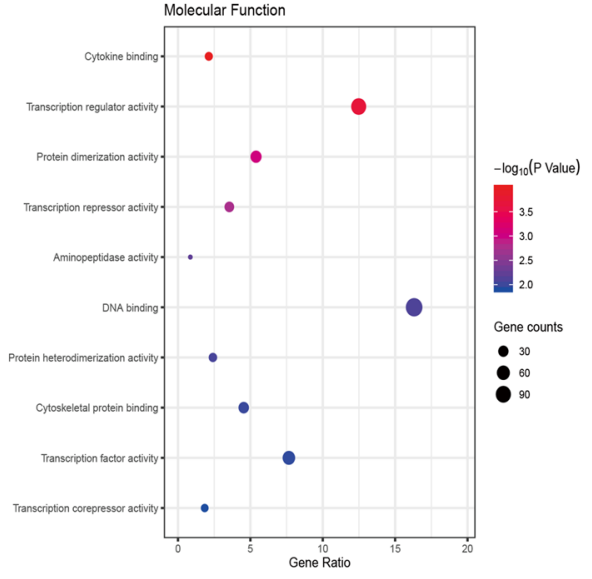

e

GSE1460_DP_THYMOCYTE_VS_NAIVE_CD4_TCELL_ADU

LT_BLOOD_UP

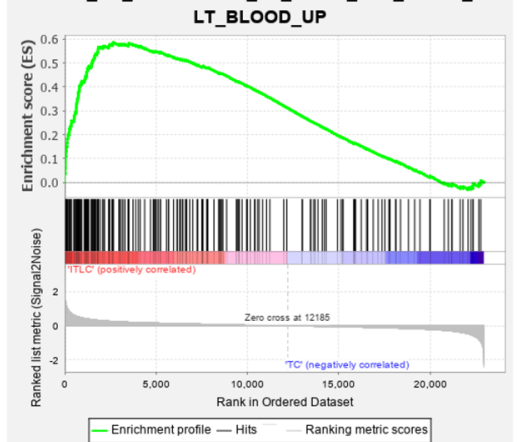

g

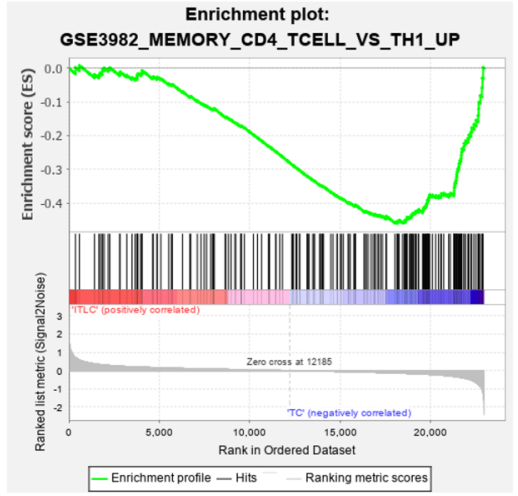

b

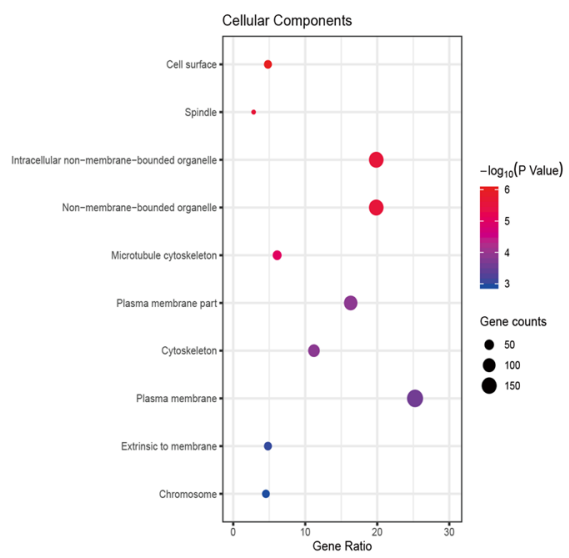

d

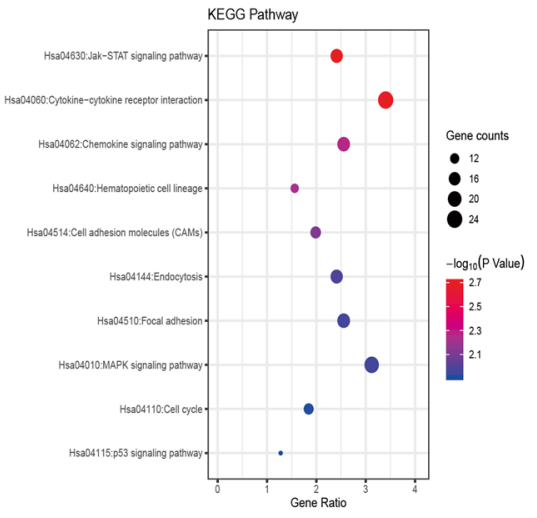

f Enrichment plot:

GSE26156 DOUBLE POSITIVE VS CD4 SINGLE POSITI

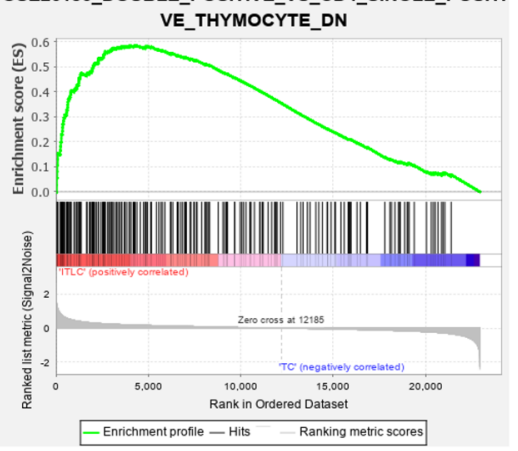

$\mathrm{h}$

Enrichment plot: GSE13738_RESTING_VS_TCR_ACTIVATED_CD4_TCELL_ UP

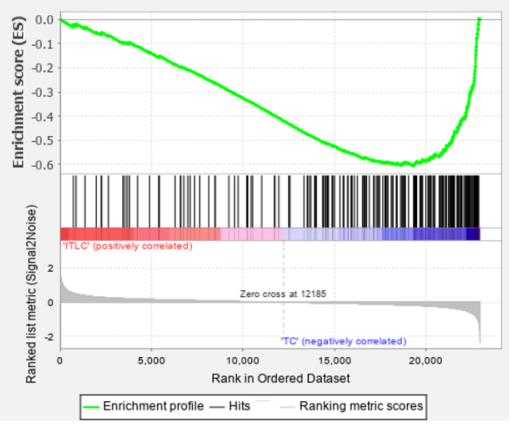


Table 2 GO functional and KEGG pathway enrichment analysis of DEGs

\begin{tabular}{|c|c|c|c|c|}
\hline ID & Terms & Count & $P$ value & Genes \\
\hline \multicolumn{5}{|c|}{ Biological process } \\
\hline GO:0051249 & $\begin{array}{l}\text { Regulation of lymphocyte } \\
\text { activation }\end{array}$ & 27 & $2.37 \mathrm{E}-10$ & LST1, VCAM1, STAT6, CD47, IFNG, ZAP70, BCL6, FAS, IL6, CTLA4... \\
\hline GO:0022403 & Cell cycle phase & 46 & $1.62 \mathrm{E}-09$ & BCAT1, NEK2, TTK, BCL2, EGFR, CDK1, KIF15, PIM1, TPX2, ATM... \\
\hline GO:0002694 & $\begin{array}{l}\text { Regulation of leukocyte } \\
\text { activation }\end{array}$ & 27 & $3.09 \mathrm{E}-09$ & $\begin{array}{l}\text { CD74, VCAM1, STAT6, CD47, IFNG, ZAP70, BCL6, FAS, CD24, IL6, CTLA4, } \\
\text { LAT, CD38, CD80... }\end{array}$ \\
\hline GO:0000278 & Mitotic cell cycle & 42 & $5.05 \mathrm{E}-09$ & BCAT1, HAUS5, NEK2, TTK, BCL2, EGFR, CDK1, KIF11, KIF15, PIM1_.. \\
\hline GO:0000087 & $\begin{array}{l}\text { M phase of mitotic cell } \\
\text { cycle }\end{array}$ & 31 & $8.52 \mathrm{E}-09$ & $\begin{array}{l}\text { HAUS5, NEK2, NEDD9, CEP55, PTTG1, CCNG2, TUBB, NCAPG, BUB1, } \\
\text { BUB3... }\end{array}$ \\
\hline \multicolumn{5}{|c|}{ Cellular components } \\
\hline GO:0009986 & Cell surface & 34 & $9.58 \mathrm{E}-07$ & CAV1, CXCR2, TIMP2, SDC4, CD74, VCAM1, FAS, CD6, IL2RB, IL6R... \\
\hline GO:0005819 & Spindle & 20 & $2.49 \mathrm{E}-06$ & CDK1, HAUS5, KIF11, NEK2, DLGAP5, KIF15, TPX2, TTK, MID1, ATM... \\
\hline GO:0043232 & $\begin{array}{l}\text { Intracellular non- } \\
\text { membrane-bounded } \\
\text { organelle }\end{array}$ & 140 & $2.64 \mathrm{E}-06$ & $\begin{array}{l}\text { STRN, TTK, PDLIM1, MRPS31, KLHL3, KIF13A, ANK3, ASPM, OXR1, } \\
\text { GNL3... }\end{array}$ \\
\hline GO:0043228 & $\begin{array}{l}\text { Non-membrane-bounded } \\
\text { organelle }\end{array}$ & 140 & $2.64 \mathrm{E}-06$ & VAPA, PDLIM5, STRN, TTK, KLHL3, HOOK1, KIF13A, ANK3, OXR1, GNL3... \\
\hline GO:0015630 & Microtubule cytoskeleton & 43 & $9.16 \mathrm{E}-06$ & HAUS5, VAPA, NEK2, TTK, NEDD9, EZR, BUB1, CDK1, KIF11, NIN... \\
\hline \multicolumn{5}{|c|}{ Molecular functions } \\
\hline GO:0019955 & Cytokine binding & 15 & $1.01 \mathrm{E}-04$ & $\begin{array}{l}\text { IL2RB, NOG, TGFBR2, IL6R, CXCR3, IL11RA, CCR9, CCR5, CXCR6, } \\
\text { CXCR5... }\end{array}$ \\
\hline GO:0030528 & $\begin{array}{l}\text { Transcription regulator } \\
\text { activity }\end{array}$ & 88 & $2.00 \mathrm{E}-04$ & FOSL2, BACH2, PTTG1, EGR1, CTBP2, YY1, SCAI, LEF1, FOSB, ID3... \\
\hline GO:0046983 & $\begin{array}{l}\text { Protein dimerization } \\
\text { activity }\end{array}$ & 38 & $9.01 \mathrm{E}-04$ & NOG, FOSL2, BACH2, TPD52, BATF, BCL2, FOSB, IL6R, FOXP1, JUN... \\
\hline GO:0016564 & $\begin{array}{l}\text { Transcription repressor } \\
\text { activity }\end{array}$ & 25 & 0.001789 & HOXC6, AES, BCL11A, BCL6, SKIL, TCF4, BCOR, IKZF4, SCAI, FOXP1_.. \\
\hline GO:0004177 & Aminopeptidase activity & 6 & 0.006034 & LNPEP, ERAP1, DPP8, ERAP2, PHEX, DPP4 \\
\hline \multicolumn{5}{|c|}{$K E G G$ pathways } \\
\hline hsa04630 & $\begin{array}{l}\text { Jak-STAT signaling } \\
\text { pathway }\end{array}$ & 17 & $1.95 \mathrm{E}-03$ & IL2RB, IL6, STAT5B, PIM1, IL6R, SOCS5, IL11RA, STAT6, IFNG, AKT3... \\
\hline hsa04060 & $\begin{array}{l}\text { Cytokine-cytokine recep- } \\
\text { tor interaction }\end{array}$ & 24 & $2.03 \mathrm{E}-03$ & EGFR, IL2RB, IL6, TNFSF4, CXCR2, IL6R, CXCR3, IL11RA, IL17RA, FAS... \\
\hline hsa04062 & $\begin{array}{l}\text { Chemokine signaling } \\
\text { pathway }\end{array}$ & 18 & $5.44 \mathrm{E}-03$ & $\begin{array}{l}\text { VAV3, STAT5B, CXCR2, CXCR3, PRKCB, CCR9, CCR5, RAC2, CXCL13, } \\
\text { AKT3... }\end{array}$ \\
\hline hsa04640 & $\begin{array}{l}\text { Hematopoietic cell } \\
\text { lineage }\end{array}$ & 11 & $5.90 \mathrm{E}-03$ & CD38, CR1, GP5, IL6, CD37, TFRC, CD59, CSF3R, IL6R, ITGA4... \\
\hline hsa04514 & $\begin{array}{l}\text { Cell adhesion molecules } \\
\text { (CAMs) }\end{array}$ & 14 & $7.55 \mathrm{E}-03$ & $\begin{array}{l}\text { CADM1, CTLA4, CDH1, ITGA4, SDC4, VCAM1, CD80, CD58, HLA-DOA, } \\
\text { CD6... }\end{array}$ \\
\hline
\end{tabular}

cell death respectively. Moreover, Gene Set Enrichment Analysis (GSEA) was implemented between TNBC and PB groups. Results revealed that gene sets were largely enriched in double-positive lymphocytes and activated $\mathrm{CD} 4{ }^{+} \mathrm{T}$ cells (Fig. 2e-h). High expression levels of FAS and CTLA4 were found in $\mathrm{CD} 4^{+} \mathrm{T}$ cells from TNBC samples. Increasing evidences support that CTLA4 was highly expressed in Treg with essential roles in repressing anticancer immunity and maintaining self-tolerance [38]. FAS molecules in tumor-infiltrating lymphocytes interacting with FAS ligand may result in the increase of apoptosis of these cells. These analyses reflect an activated or exhausted state of the $\mathrm{CD} 4^{+}$ the TILs.

\section{Visualization and evaluation of $\mathrm{CD}^{+} \mathrm{T}$-cell subsets infiltration}

CIBERSORT, a deconvolution algorithm method based on gene expression, was used to predict the constituent of multiple immune cell types in the tumor tissue admixtures. The 
a

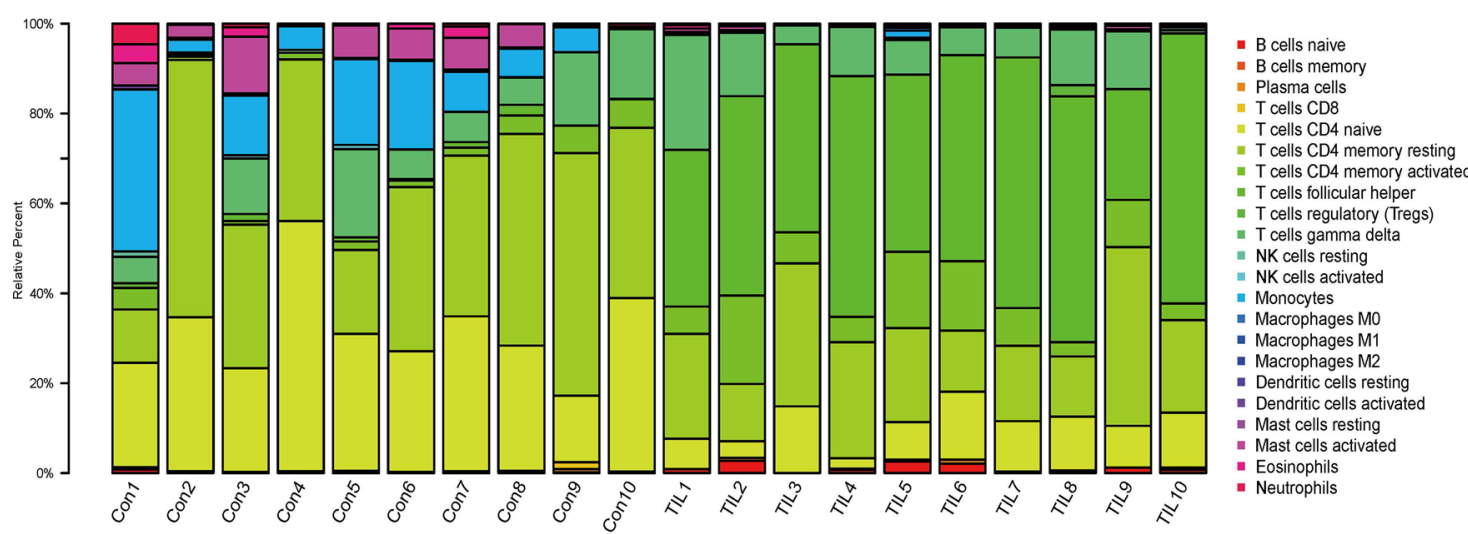

b
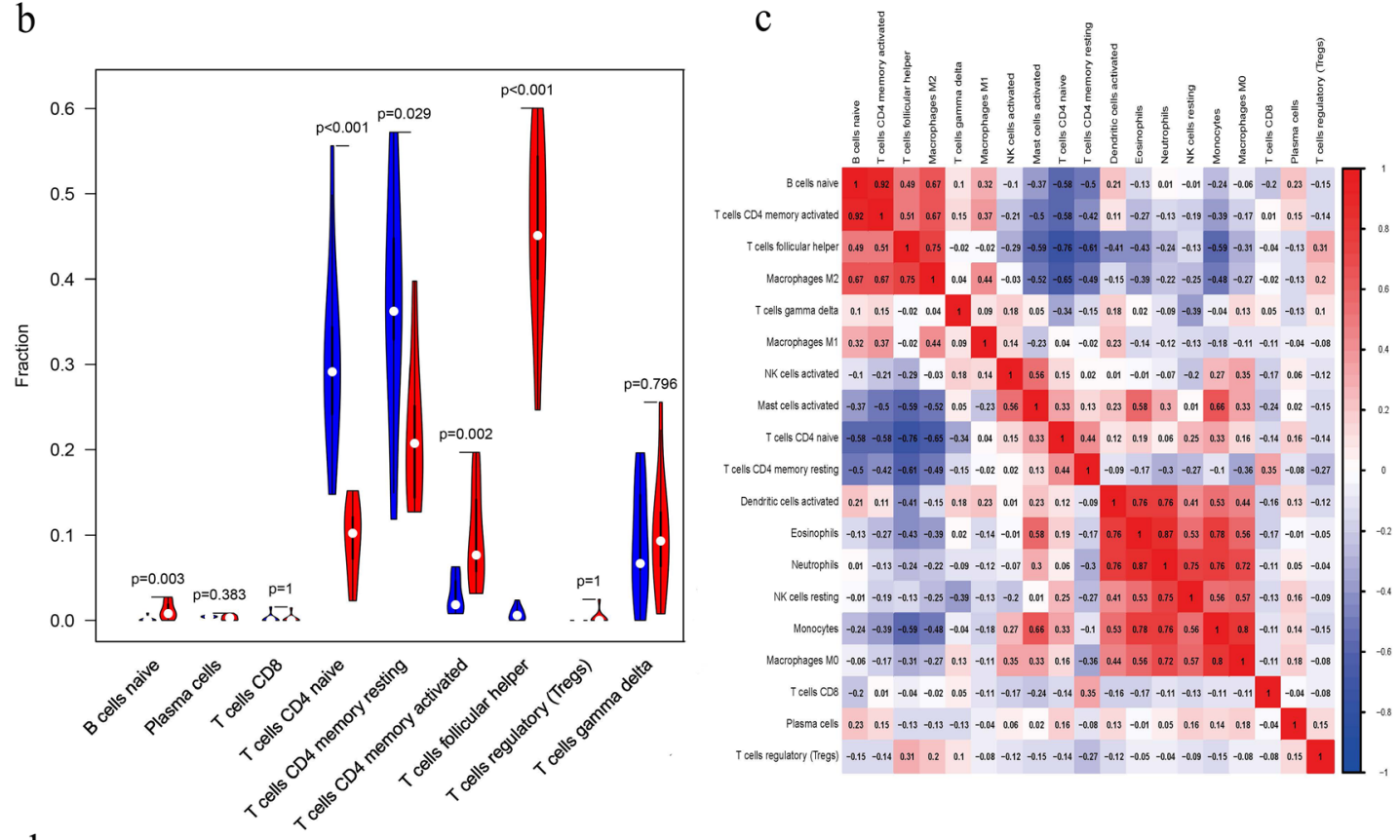

d

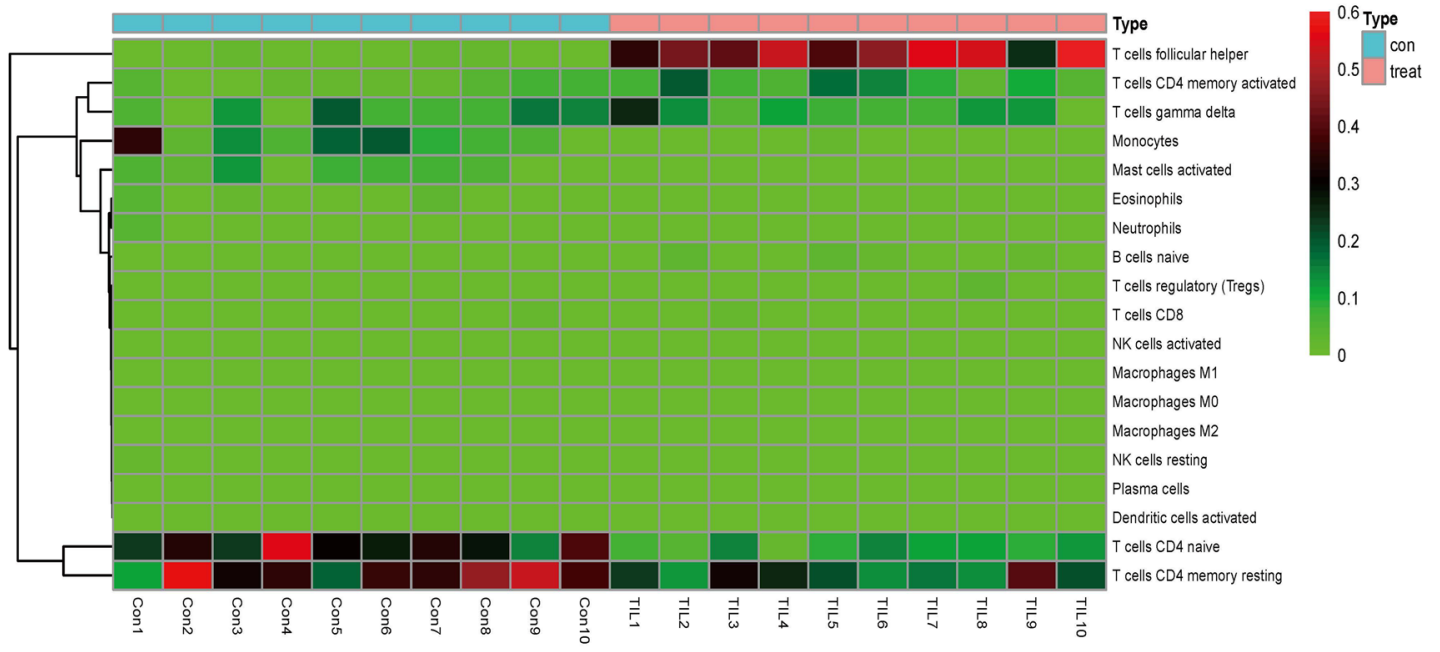


4Fig. 3 Landscape of $\mathrm{CD}^{+}$T-cell subsets infiltrated in TNBC. a Bar plot of immune infiltration of the isolated $\mathrm{CD} 4^{+} \mathrm{T}$ cells from TNBC tissues and PB samples. b The violin plot of the immune cell proportions. c Correlation matrix of all the immune cell proportions between TNBC tissues and PB samples. d Heat map of the 22 immune cell proportions between TNBC tissues and PB samples. Pearson chi-squared test was utilized to perform correlation analysis

cellular composition can be evaluated based on standardized gene expression value, which indicates the abundances of specific cell types. In this study, we first explored CD4 ${ }^{+}$ TILs in TNBC tissue by the CIBERSORT algorithm. Various proportions of the $\mathrm{CD}^{+}{ }^{+} \mathrm{T}$-cell subsets in each TNBC sample were shown in different colors, and the levels of the immune cell populations were displayed by the length of the bars in the bar chart (Fig. 3a). From the chart of Fig. 3b, we identified a relatively high percentage of follicular helper $\mathrm{T}$ cells $(P<0.001)$, whereas a significantly low percentage of $\mathrm{CD}^{+}$naive $\mathrm{T}$ cells was found in the TILs $(\mathrm{P}<0.001)$. Result revealed that $\mathrm{T}$ cells follicular helper were inversely correlated with $\mathrm{T}$ cells $\mathrm{CD}^{+}$naive and memory resting $\mathrm{T}$ cells ( $r=-0.76$ and $r=-0.61$, respectively), which suggested an antagonistic function of Tfh with the two cell types in TNBC (Fig. 3c). The correlations between these differentially expressed types of immune cells were shown in Fig. 3d. Based on the 22 immune cells subpopulation, the isolated TILs were further divided into 2 discrete groups using the hierarchical clustering. The aberrant immune cell infiltration especially the increased $\mathrm{CD} 4^{+}$memory activated $\mathrm{T}$ cells may have an important clinical value in TNBC.

\section{Identification of hub genes and analyzing the modules of the networks}

To investigate the gene expression module of tumor-infiltrating $\mathrm{CD}^{+} \mathrm{T}$ cells results in the influence of tumor microenvironment, protein-protein interaction (PPI) networks were generated using the significantly expressed DEGs (Fig. 4a). To characterize the attributes of the key nodes in the PPI network, two networks mainly associated with the core proteins were identified to be candidate markers, which may exert significant influence on the biological function of the $\mathrm{CD} 4^{+}$ T cells (Fig. 4b, c). The two networks consisted of 63 nodes, 87 edges and 39 nodes, 61 edges respectively. To further identify the hub genes and key pathways, EPC (Edge Percolated Component) and shortest path analyses were conducted by CytoHubba plug-in in Cytoscape. It is worth noting that CXCR5 was differentially up-regulated and directly interacted with CXCR6 (Fig. 4c). The most significant module composed of five nodes including FAS, IFNG, CXCR6, CTLA4 and JUN were screened out from the network with a connectivity degree $>18$ (Fig. 4d). Functional annotation and pathway enrichment of these nodes in the above-mentioned networks showed that they were primarily associated with activation of immune response and chemotaxis (Fig. 4e, f). The heatmap demonstrated that all of the five hub genes are significantly up-regulated in the TILs of the TNBC samples (Fig. 4g). Furthermore, the expression pattern of CD4 ${ }^{+}$ $\mathrm{T}$ cells isolated from peripheral blood of TNBC patients was compared with that of healthy donor blood. Protein-protein interaction (PPI) network was generated using the significantly expressed DEGs (Supplementary Fig. 2a). Two major networks related to the core nodes were presented in Supplementary Fig. 2b, c in which four significantly up-regulated genes including CTLA4, JUN, CXCR6, and CXCL13 whose expression levels also markedly increased in $\mathrm{CD} 4^{+} \mathrm{T}$ cells infiltrated in TNBC tissue compared with the cells in peripheral blood of TNBC patients. However, FAS was not found highly expressed in the tumor "macro"-environment. Moreover, CXCL13, IFNG, FN1, SPP1, and CXCR6 were screened as the hub genes from the significantly expressed DEGs and showed in Supplementary Fig. 2d.

\section{Validation of the chemotaxis and immune response-related hub genes}

The expression pattern of the above five differentially expressed hub genes in clinical samples were evaluated by quantitative PCR and shown as Fig. 5a-e. Results showed that mRNA expression levels of these genes were significantly increased in tumor-infiltrating $\mathrm{CD} 4^{+} \mathrm{T}$ cells compared with the cells from the PB of TNBC patients. ROC (receiver operating characteristic) analysis was then analyzed for all of the hub genes (Fig. $5 f-j$ ), and areas under the curve (AUC) of CTLA4, CXCR6, FAS, IFNG, and JUN were 0.9733, 0.9644, 1.000, 0.9689 and 1.000, respectively $(P<0.01)$. The AUC represented the set of all possible statistical tests of the expression data with equal probability for a true positive and a false positive result based on each decision threshold value [39]. Expression linear correlations between two groups among these hub 
a

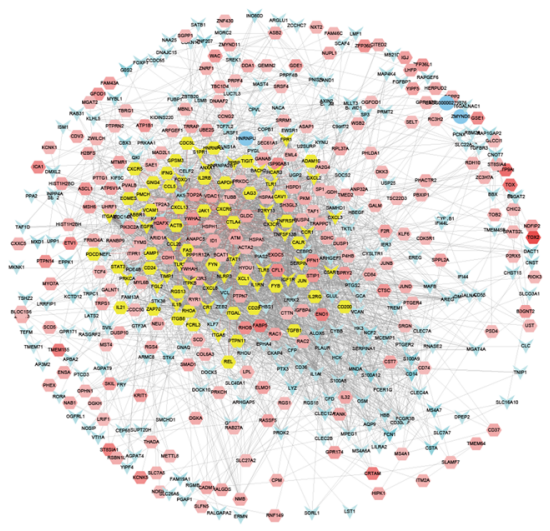

c

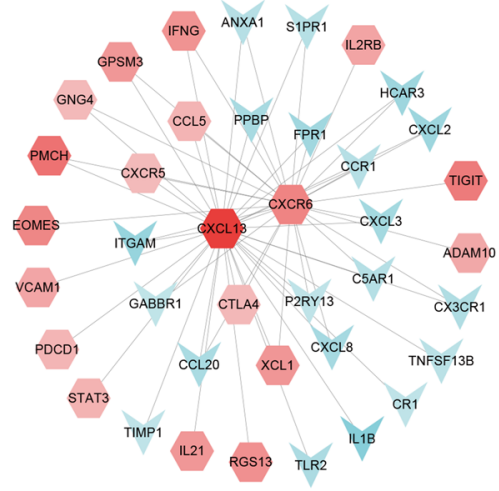

e
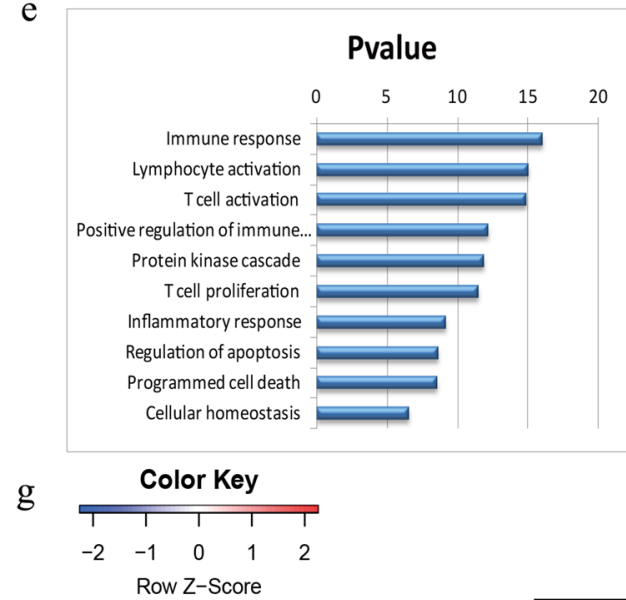

b

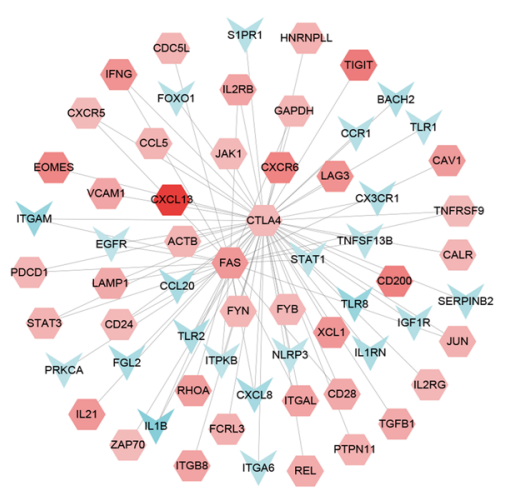

d

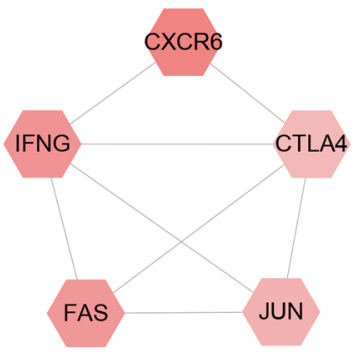

f

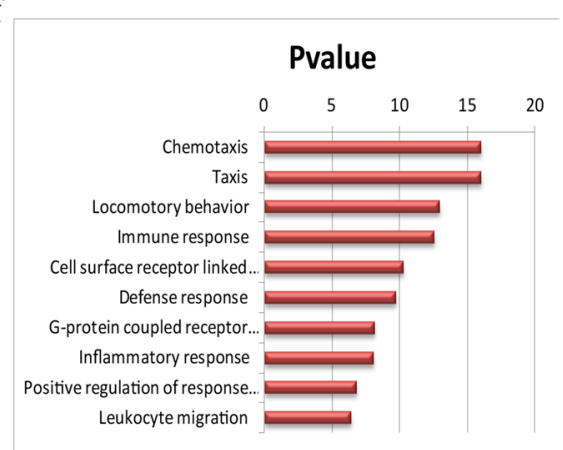

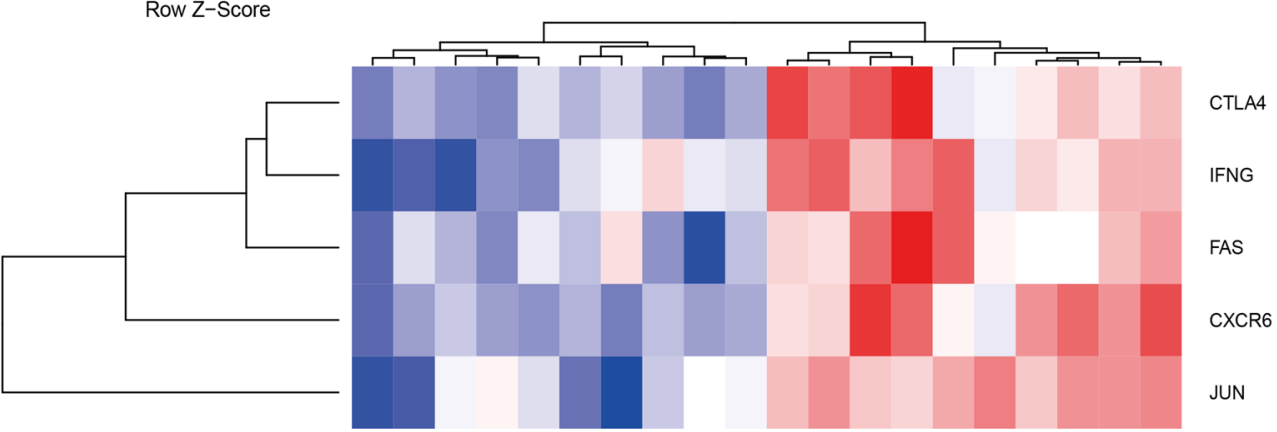

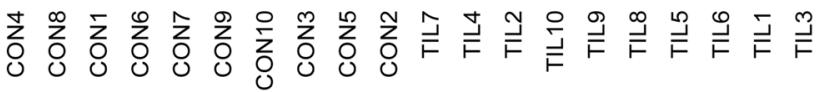


4Fig. 4 PPI networks and involved signal pathways. a Network of the DEGs from the microarray data. b Network derived from panel A with first neighbors associated with the core proteins CTLA4 and FAS. c Network derived from panel A with first neighbors associated with the core proteins CXCL13 and CXCR6. d Significant hub nodes extracted from network b. e Signal pathways involved in network $\mathbf{b}$. $\mathbf{f}$ Signal pathways involved in network c. g Heatmap of the significant hub genes

genes were shown as Fig. 5k-p, in which CTLA4, FAS and JUN were in good consistency.

\section{Significance of extensive infiltration of CD4 ${ }^{+}$TIL subsets and key proteins identification}

The presence of $\mathrm{CD}^{+}{ }^{+} \mathrm{T}$ cell subset profiles in the TILs was reanalyzed applying IMMUCELL AI criteria. Results showed that the intratumoral $\mathrm{CD}^{+} \mathrm{T}$ cell profiles were significantly enriched in nTreg $(P<0.001)$, Th17 $(P<0.001)$, Tfh $(P=0.014)$, and exhausted cells $(P<0.001)$ whereas the central memory $(P=0.0017), \mathrm{CD} 4$ naive $(P<0.001)$, cytotoxic $(P<0.001)$, and NKT cells $(P=0.019)$ were significantly decreased in the CD4 ${ }^{+}$TILs (Fig. 6a), which is consistent with the results analyzed by CIBERSORT algorithm. Immunofluorescence labeling of $\mathrm{CD}^{+}{ }^{+} \mathrm{T}$ cells infiltrated in normal breast tissue was performed (Supplementary Fig. 3a) and the proportion of the $\mathrm{CD} 4^{+} \mathrm{T}$ cells were evaluated and showed in Supplementary Fig. 3b-e. To further illustrate the immune cell profiles, we detected the apoptotic cells by TUNEL staining assay and observed that the apoptotic TILs are significantly increased in the TNBC microenvironment $(P<0.001)$. We also found the increased expression of the protein of CTLA4, CXCR6, and FAS in the CD4 ${ }^{+}$TILs of the clinical samples (Fig. 6b-e). In addition, apoptotic cells infiltrated in the normal breast tissues were detected (Supplementary Fig. 3g) and quantitative evaluation of the apoptotic $\mathrm{T}$ cells in breast tumor and normal tissue were presented in Supplementary Fig. 3f, h.

\section{Discussion}

Tumor-infiltrating lymphocytes are a kind of mononuclear immune cells. The intratumoral lymphocytes phenotypes consisted of varying proportions of $\mathrm{CD} 4^{+} \mathrm{T}$ cells, $\mathrm{CD} 8^{+} \mathrm{T}$ cells, B cells and NK cells, whereas, T cells were the main phenotype and significantly associated with pathological characteristics of the patients. A growing number of studies have suggested that TILs can be used to predict clinical outcome and treatment response of various tumors [40, 41]. It is indicated that the diversified $\mathrm{CD}^{+} \mathrm{T}$ cell cloning responses may reflect the diversification of neoantigens of cancer cells. Actually, studies showed that increased infiltration of memory $\mathrm{T}$ cells and mature $\mathrm{T}$ cells are closely associated with a favorable prognosis [42], but immunosuppressive regulatory T cells are opposite [43].

In this study, it is showed that infiltrated lymphocytes were significantly increased in the TME of triple-negative breast cancers (TNBCs). Furthermore, the relationship between the Th gene expression profile and the level of lymphocytes was investigated, which reflects the degree of TILs infiltration in TNBC samples. Another study also demonstrated increased infiltration of TILs in TNBC tissues [44] which is consistent with our results. In addition, our analytic result showed that cytotoxic and central memory $\mathrm{T}$ cells were significantly reduced, whereas regulatory $\mathrm{T}$ cells, Tfh and exhausted T cells were significantly increased in TNBC patients (Fig. 6a). Traditionally, activated memory T cellmediated immunity is considered to be antitumoral, since patients with higher levels of active memory $\mathrm{T}$ cells are predicted to have longer-term disease-free survival. However, tumors infiltrated with polarized Treg and Tfh subpopulations were suggested an immunosuppressive microenvironment and a poorer prognosis of TNBC patients [45]. Th17 cells have been shown to work synergistically with IFN- $\gamma$ to produce important antitumor chemokines CXCL10 and CXCL9; however, research indicated that IL-17 was a predictor of poor prognosis in hepatocellular carcinoma patients [46], suggesting the antitumor and protumor immune responses reports may be context dependent.

From the network, we found that the expression levels of FAS and CTLA4 were markedly increased in intratumoral $\mathrm{CD}^{+}{ }^{+} \mathrm{T}$ cell of TNBC samples. As a death receptor, FAS recruits the adaptor protein procaspase- 8 when it interacts with FasL to form a death-inducing signal complex (DISC), consequently leading to the proteolytic stimulation of apoptosis [47]. Previous studies have shown that IFN- $\gamma$ treatment could up-regulate Fas expression level in multiple cell types and tumors as well as promote Fas-mediated apoptosis [48, 49]. CTLA-4, as an inhibitory immune checkpoint, the 
a

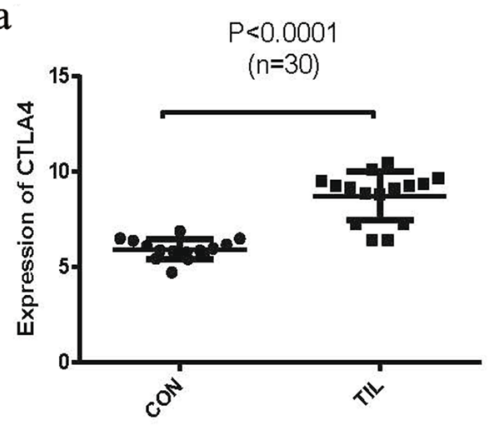

d

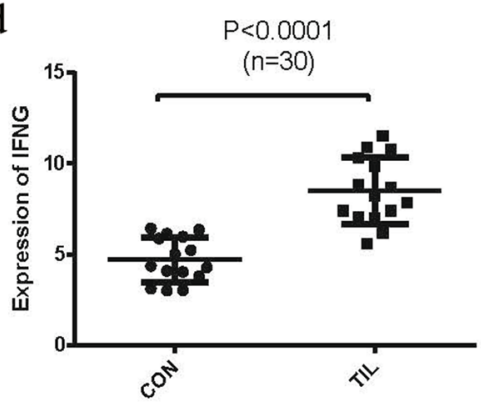

g

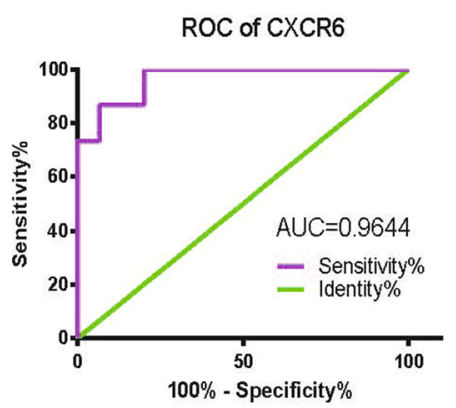

j

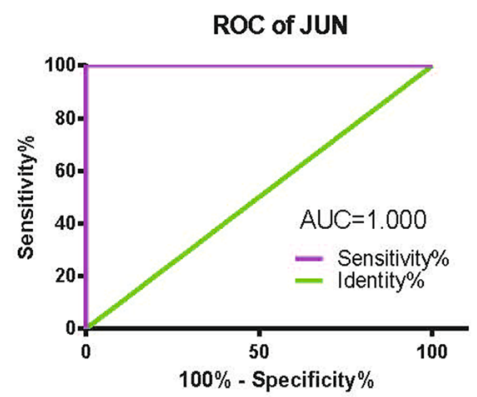

$\mathrm{m}$

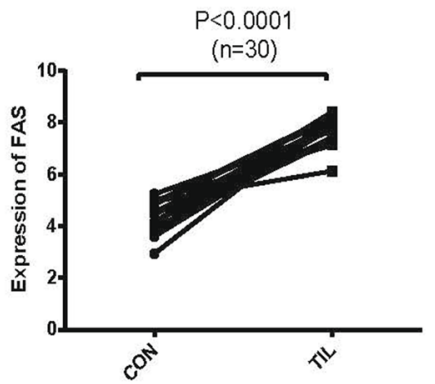

b

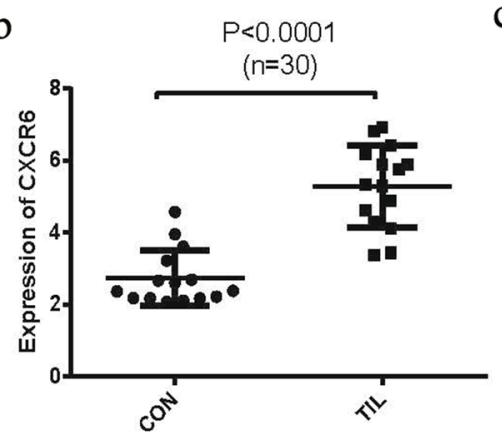

e

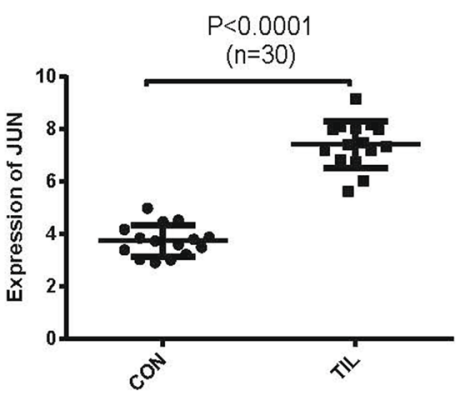

$\mathrm{h}$

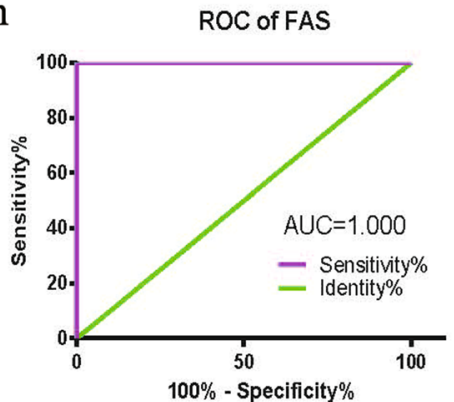

k

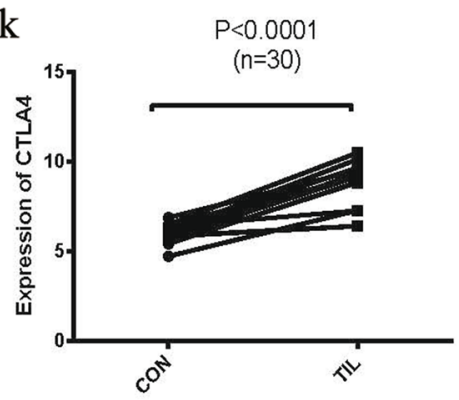

n

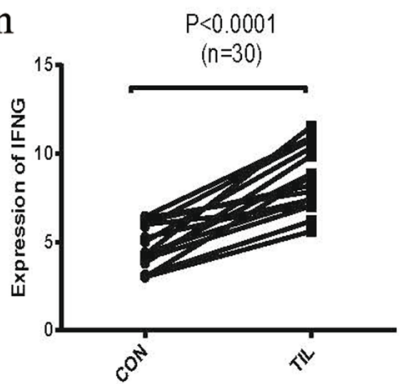

c

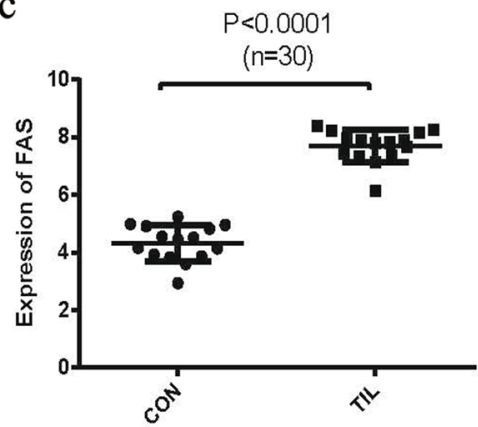

f

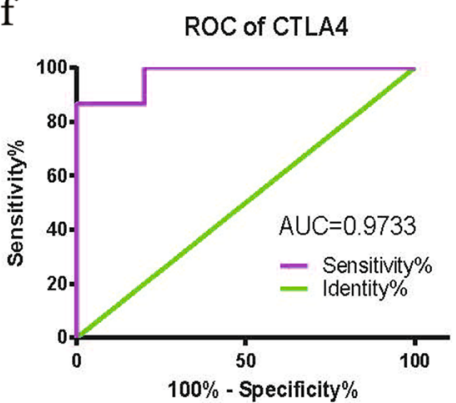

i

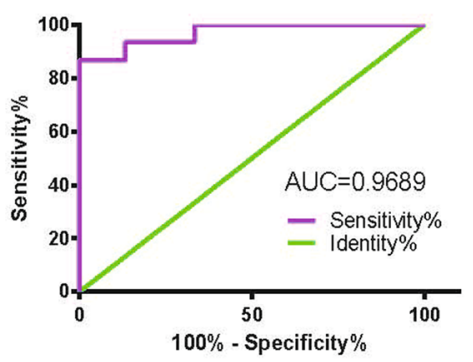

1

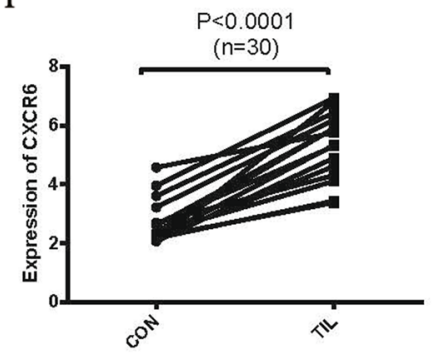

$\mathrm{p}$

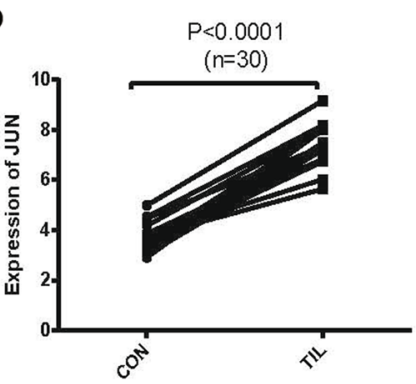


4 Fig. 5 Comparable evaluation of the expression patterns and ROC analysis of the five differentially expressed genes. a-e Expression levels of CTLA4, CXCR6, FAS, IFNG, and JUN in CD4 ${ }^{+} \mathrm{T}$ cells isolated from TNBC tissues and PB samples respectively. $\mathbf{f}-\mathbf{g}$ ROC curves to estimate the consistency of the expression values between TNBC tissues and PB samples. k-p Expression linear correlations between the two groups of TNBC and PB samples

expression level of which was remarkably higher in basallike TNBC and HER2-enriched tissues compared with the other BC molecular subtypes [50]. CTLA4 plays an important role in negatively immunomodulating the activity of $\mathrm{T}$ lymphocytes via cell extrinsic and intrinsic pathways. Cell extrinsic events such as the competition with CD28 in binding to its legends CD80/86, lead to T cell unresponsiveness due to inhibitory signals delivered [51]. Intrinsic events include the inhibition of protein translation, activation of ubiquitin ligases, recruitment of phosphatases, and inhibition of cytokine receptor signaling [52]. Checkpoint inhibitors against this $\mathrm{T}$ cell exhaustion marker have been demonstrated to be effective in both preclinical models and patients.

In this study, we found that CXCR5, CXCR6 and CXCL13 involved in the pathway of chemotaxis are overexpressed in the network (Supplementary Table 1, Fig. 4c, f). Study demonstrated that CXCR5 and CXCL13 were also highly expressed in TILs from NSCLC cancer [53]. Go and pathway analysis indicated CXCR6 and CXCR5 were also implicated in the locomotory behavior molecule pathway in our study (Supplementary Table 1 and Fig. 4f). Previous research revealed that systemic used of IFN- $\gamma$ could drive inflammation and facilitate $\mathrm{T}$ cell infiltration in cold tumors [54]. Therefore, we speculate that the abovementioned highly expressed molecules might contribute to the infiltration of $\mathrm{T}$ cells, and consequently results in a hot TME in BC. In addition, JUN, a putative transforming and remodeling gene, high expression of these molecules in $\mathrm{CD} 4{ }^{+}$TILs might contribute the cells epigenome vulnerable to immunoediting with the cancer development. Meanwhile, Jak - STAT3 signaling pathway was significantly activated which is well-known for its key role in the recruitment of myeloid-derived suppressor cells to TME and exertion of their immunosuppressive effect [55].

\section{Conclusion}

Our study revealed that cytotoxic and memory $\mathrm{T}$ cells significantly decreased, whereas regulatory $\mathrm{T}$ cells and apoptotic T cells markedly increased in TNBC patients. Tumors infiltrated with polarized regulatory $\mathrm{T}$ cells were suggested an immunosuppressive microenvironment and a poorer prognosis of TNBC patients [56, 57]. By comparing the profiles of the whole immune cells from TNBC tissue with that from normal breast tissue, we found that although Treg cells increased, but there is no significance (Supplementary Fig. 4). The reason for this phenomenon may due to the variety subsets of the lymphocytes in whole immune cells in which the small number of $\mathrm{CD}^{+} \mathrm{T}$ Treg lead to its lots of information was concealed by the gene expressive abundance of all lymphocytes. Meanwhile, the expression level of CTLA4 and FAS were markedly increased in intratumoral $\mathrm{CD} 4^{+}$ $\mathrm{T}$ cell, which may play an essential role in maintaining self-tolerance as well as suppressing anticancer immunity. On the other hand, CXCR5, CXCR6 and CXCL13 were involved in chemotaxis, locomotory behavior and leukocyte migration (Supplementary Table 1, Fig. 4c, f). Over-expression of CXCR5, CXCR6 and CXCL13 may be associated with CXCL13/CXCR5 signaling axis involved in immune cell trafficking to the TME. However, this signaling axis could also modulate cancer cell ability to grow, proliferate, invade, and metastases through IL-10 secretion as well as recruit Treg cells and myeloid-derived immunosuppressive cells to the tumor microenvironment [58-60]. Therefore, for generating novel therapeutics, it will be important to develop Treg cell-targeted therapies or facilitate precision medicine focusing on CXCL13/CXCR5 signaling axis to enhance the adaptive antitumor immunity. Nevertheless, it reminds us of some limitations in the analysis since various gene interactions result in different various cellular conditions and functional heterogeneity of the CD4 ${ }^{+}$TILs. This exploratory analysis still provides suggestions of potential candidate genes as well as the signal pathways underlying tumor-infiltrating $\mathrm{CD} 4^{+} \mathrm{T}$ cells in TME and bestows a theranostic perspective to the current trend of research. 

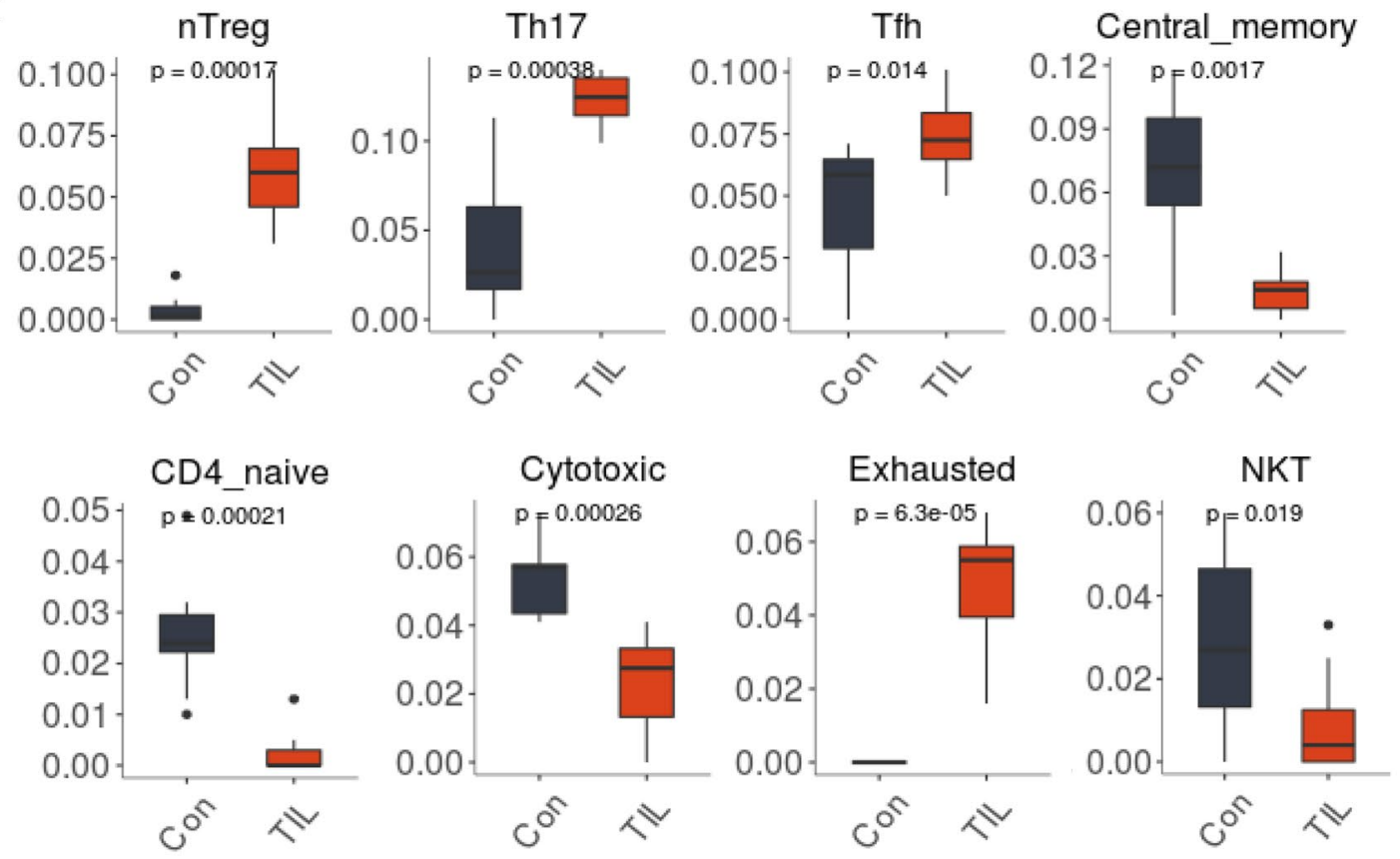

b
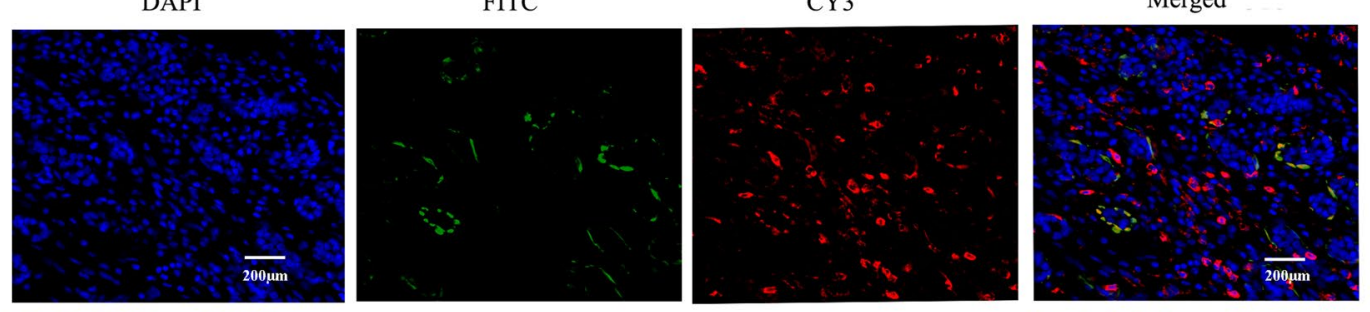

C
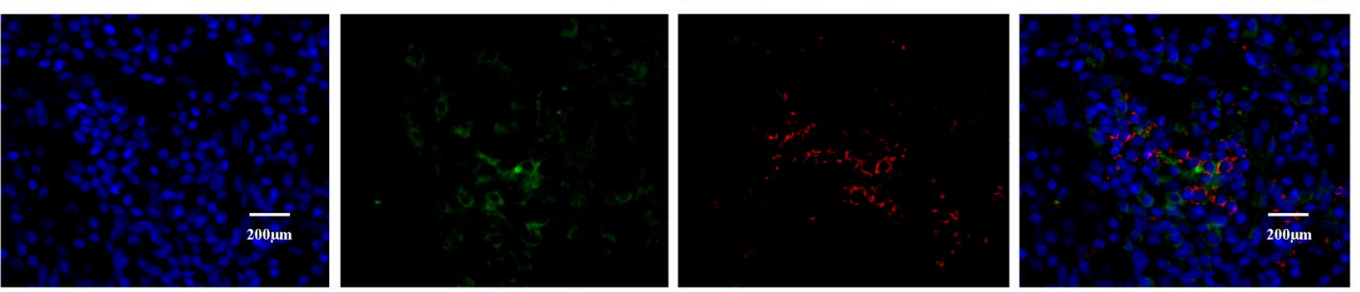

d
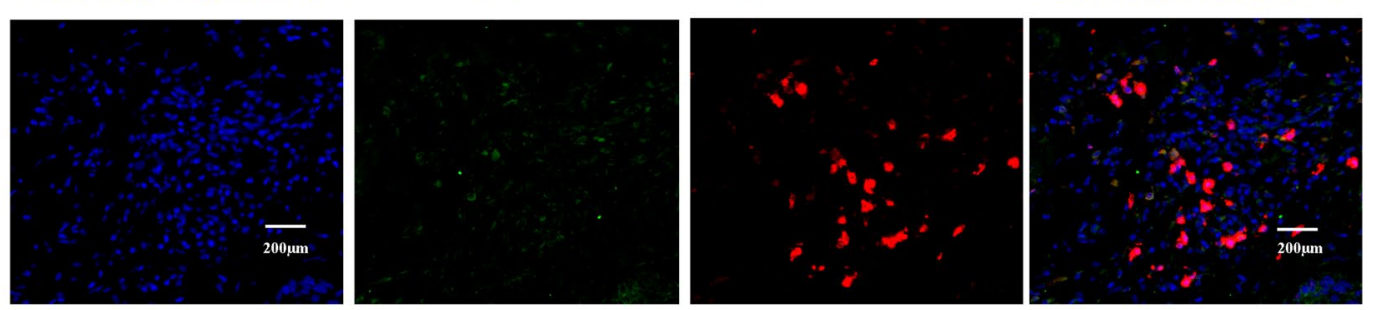

$\mathrm{e}$
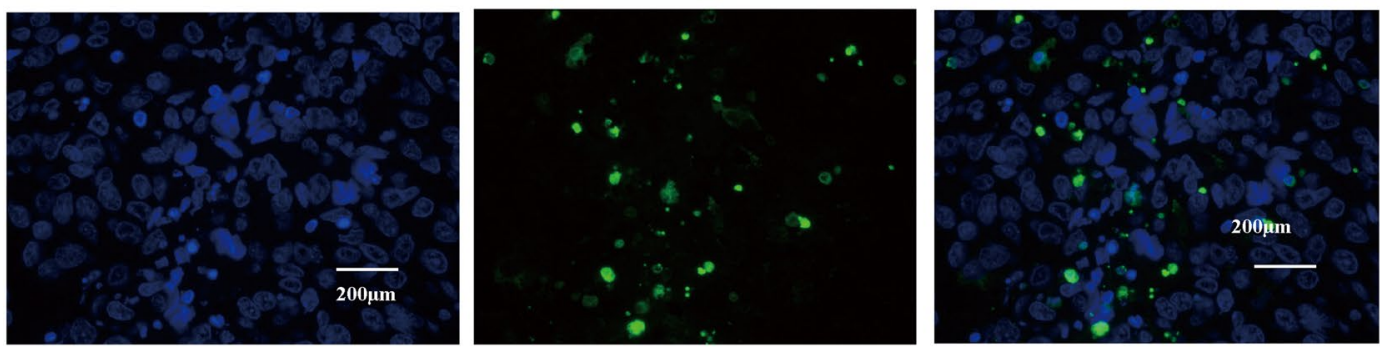

Fig. $6 \mathrm{CD}^{+}$T-cell subset profiles and immunofluorescence image of CTLA4, CXCR6, FAS in TNBC tissue. a $\mathrm{CD}^{+} \mathrm{T}$ cell subset profiles in the TNBC. Immunofluorescence labeling for $\mathbf{b}$ CD4 (red) and
CTLA4 (green), c CD4 (red) and CXCR6 (green), d CD4 (red) and FAS (green) as well as merged images. e Detection of the apoptosis cells infiltrated in the tumor tissues. $(n=6, P<0.05,200 \mathrm{X})$ 
Authors contributions All authors took part in writing, reviewing and editing the manuscript. SZ, GQ and $\mathrm{HZ}$ designed experiments; $\mathrm{HZ}, \mathrm{GQ}, \mathrm{XH}$ and HY performed experiments; SZ, HZ and XH prepared figures; All authors reviewed the manuscript and approved it for publication.

Funding This study was supported by Grants from Natural Science and Technologies Program of Henan Province (172102410018).

Data availability The data of this study have been deposited in the Gene Expression Omnibus repository GSE150814 (https://www.ncbi. nlm.nih.gov/geo/query/acc.cgi?acc=GSE150814).

\section{Compliance with ethical standards}

Conflict of interest The authors have no conflict of interests.

Ethical approval Tissue and serum samples were collected from patients after obtaining informed consent in accordance with a protocol approved by the Ethics Committee of Affiliated Cancer Hospital and the First Affiliated Hospital of Zhengzhou University (Zhengzhou, China).

Open Access This article is licensed under a Creative Commons Attribution 4.0 International License, which permits use, sharing, adaptation, distribution and reproduction in any medium or format, as long as you give appropriate credit to the original author(s) and the source, provide a link to the Creative Commons licence, and indicate if changes were made. The images or other third party material in this article are included in the article's Creative Commons licence, unless indicated otherwise in a credit line to the material. If material is not included in the article's Creative Commons licence and your intended use is not permitted by statutory regulation or exceeds the permitted use, you will need to obtain permission directly from the copyright holder. To view a copy of this licence, visit http://creativecommons.org/licenses/by/4.0/.

\section{References}

1. Harbeck N, Gnant M (2017) Breast cancer. Lancet 389(10074):1134-1150

2. Guo M, Liu T, Li P, Wang T, Zeng C, Yang M, Li G, Han J, Wu W, Zhang R (2019) Association between metabolic syndrome and breast cancer risk: an updated meta-analysis of follow-up studies. Front Oncol 9:1290

3. Oner G, Altintas S, Canturk Z, Tjalma W, Verhoeven Y, Van Berckelaer C, Berneman Z, Peeters M, Pauwels P, van Dam PA (2019) Triple-negative breast cancer-Role of immunology: a systemic review. Breast J 26(5):995-999

4. Liyanage UK, Moore TT, Joo HG, Tanaka Y, Herrmann V, Doherty G, Drebin JA, Strasberg SM, Eberlein TJ, Goedegebuure PS, Linehan DC (2002) Prevalence of regulatory T cells is increased in peripheral blood and tumor microenvironment of patients with pancreas or breast adenocarcinoma. J Immunol 169(5):2756-2761

5. Emerson DA, Redmond WL (2018) Overcoming tumor-induced immune suppression: from relieving inhibition to providing costimulation with T cell agonists. BioDrugs 32(3):221-231

6. Bahrambeigi S, Shafiei-Irannejad V (2020) Immune-mediated anti-tumor effects of metformin; targeting metabolic reprogramming of $\mathrm{T}$ cells as a new possible mechanism for anti-cancer effects of metformin. Biochem Pharmacol 174:113787
7. Flament H, Alonso Ramirez R, Prémel V, Joncker NT, Jacquet A, Scholl S, Lantz O (2015) Modeling the specific $\mathrm{CD} 4+\mathrm{T}$ cell response against a tumor neoantigen. J Immunol 194(7):3501-3512

8. Carreno BM, Magrini V, Becker-Hapak M, Kaabinejadian S, Hundal J, Petti AA, Ly A, Lie WR, Hildebrand WH, Mardis ER, Linette GP (2015) Cancer immunotherapy. A dendritic cell vaccine increases the breadth and diversity of melanoma neoantigenspecific T cells. Science 348(6236):803-808

9. Mu L, Yang C, Gao Q, Long Y, Ge H, DeLeon G, Jin L, Chang YE, Sayour EJ, Ji J, Jiang J, Kubilis PS, Qi J, Gu Y, Wang J, Song Y, Mitchell DA, Lin Z, Huang J (2017) CD4+ and perivascular Foxp3+ $\mathrm{T}$ cells in glioma correlate with angiogenesis and tumor progression. Front Immunol 8:1451

10. Matsumoto H, Thike AA, Li H, Yeong J, Koo SL, Dent RA, Tan PH, Iqbal J (2016) Increased CD4 and CD8-positive T cell infiltrate signifies good prognosis in a subset of triple-negative breast cancer. Breast Cancer Res Treat 156(2):237-247

11. Al-Shibli KI, Donnem T, Al-Saad S, Persson M, Bremnes RM, Busund LT (2008) Prognostic effect of epithelial and stromal lymphocyte infiltration in non-small cell lung cancer. Clin Cancer Res 14(16):5220-5227

12. Zander R, Schauder D, Xin G, Nguyen C, Wu X, Zajac A, Cui $\mathrm{W}(2019) \mathrm{CD} 4(+) \mathrm{T}$ cell help is required for the formation of a cytolytic CD8(+) T cell subset that protects against chronic infection and cancer. Immunity 51(6):1028-1042

13. Kinoshita T, Kudo-Saito C, Muramatsu R, Fujita T, Saito M, Nagumo H, Sakurai T, Noji S, Takahata E, Yaguchi T, Tsukamoto N, Hayashi Y, Kaseda K, Kamiyama I, Ohtsuka T, Tomizawa K, Shimoji M, Mitsudomi T, Asamura H, Kawakami Y (2017) Determination of poor prognostic immune features of tumour microenvironment in non-smoking patients with lung adenocarcinoma. Eur J Cancer 86:15-27

14. Correale P, Rotundo MS, Botta C, Del Vecchio MT, Ginanneschi C, Licchetta A, Conca R, Apollinari S, De Luca F, Tassone P, Tagliaferri P (2012) Tumor infiltration by T lymphocytes expressing chemokine receptor 7 (CCR7) is predictive of favorable outcome in patients with advanced colorectal carcinoma. Clin Cancer Res 18(3):850-857

15. Bogen B, Fauskanger M, Haabeth OA, Tveita A (2019) CD4(+) $\mathrm{T}$ cells indirectly kill tumor cells via induction of cytotoxic macrophages in mouse models. Cancer Immunol Immunother 68(11):1865-1873

16. Wakabayashi O, Yamazaki K, Oizumi S, Hommura F, Kinoshita I, Ogura S, Dosaka-Akita H, Nishimura M (2003) CD4+ T cells in cancer stroma, not $\mathrm{CD} 8+\mathrm{T}$ cells in cancer cell nests, are associated with favorable prognosis in human non-small cell lung cancers. Cancer Sci 94(11):1003-1009

17. Newman AM, Liu CL, Green MR, Gentles AJ, Feng W, Xu Y, Hoang CD, Diehn M, Alizadeh AA (2015) Robust enumeration of cell subsets from tissue expression profiles. Nat Methods 12(5):453-457

18. Leko V, McDuffie LA, Zheng Z, Gartner JJ, Prickett TD, Apolo AB, Agarwal PK, Rosenberg SA, Lu YC (2019) Identification of neoantigen-reactive tumor-infiltrating lymphocytes in primary bladder cancer. J Immunol 202(12):3458-3467

19. Jin YW, Hu P (2020) Tumor-infiltrating CD8 T cells predict clinical breast cancer outcomes in young women. Cancers (Basel) 12(5):1076

20. Westergaard MCW, Andersen R, Chong C, Kjeldsen JW, Pedersen M, Friese C, Hasselager T, Lajer H, Coukos G, BassaniSternberg M, Donia M, Svane IM (2019) Tumour-reactive T cell subsets in the microenvironment of ovarian cancer. Br J Cancer 120(4):424-434

21. Adurthi S, Mukherjee G, Krishnamurthy H, Sudhir K, Bafna UD, Umadevi K, Jayshree RS (2012) Functional tumor 
infiltrating TH1 and TH2 effectors in large early-stage cervical cancer are suppressed by regulatory $\mathrm{T}$ cells. Int $\mathrm{J}$ Gynecol Cancer 22(7):1130-1137

22. Garcia-Teijido P, Cabal ML, Fernandez IP, Perez YF (2016) Tumor-infiltrating lymphocytes in triple negative breast cancer: the future of immune targeting. Clin Med Insights Oncol 10(Suppl 1):31-39

23. Iwata-Kajihara T, Sumimoto H, Kawamura N, Ueda R, Takahashi T, Mizuguchi H, Miyagishi M, Takeda K, Kawakami Y (2011) Enhanced cancer immunotherapy using STAT3-depleted dendritic cells with high Th1-inducing ability and resistance to cancer cell-derived inhibitory factors. J Immunol 187(1):27-36

24. Yu GT, Bu LL, Zhao YY, Mao L, Deng WW, Wu TF, Zhang WF, Sun ZJ (2016) CTLA4 blockade reduces immature myeloid cells in head and neck squamous cell carcinoma. Oncoimmunology 5(6):e1151594

25. Irizarry RA, Hobbs B, Collin F, Beazer-Barclay YD, Antonellis KJ, Scherf U, Speed TP (2003) Exploration, normalization, and summaries of high density oligonucleotide array probe level data. Biostatistics 4(2):249-264

26. Gautier L, Cope L, Bolstad BM, Irizarry RA (2004) affy-analysis of Affymetrix GeneChip data at the probe level. Bioinformatics 20(3):307-315

27. Reiner A, Yekutieli D, Benjamini Y (2003) Identifying differentially expressed genes using false discovery rate controlling procedures. Bioinformatics 19(3):368-375

28. da Huang W, Sherman BT, Lempicki RA (2009) Systematic and integrative analysis of large gene lists using DAVID bioinformatics resources. Nat Protoc 4(1):44-57

29. Zhu S, Min Z, Qiao X, Chen S, Yang J, Zhang X, Liu X, Ran W, Lv R, Lin Y, Wang J (2019) Expression profile-based screening for critical genes reveals S100A4, ACKR3 and CDH1 in docetaxel-resistant prostate cancer cells. Aging (Albany NY) 11(24):12754-12772

30. Subramanian A, Tamayo P, Mootha VK, Mukherjee S, Ebert BL, Gillette MA, Paulovich A, Pomeroy SL, Golub TR, Lander ES, Mesirov JP (2005) Gene set enrichment analysis: a knowledgebased approach for interpreting genome-wide expression profiles. Proc Natl Acad Sci U S A 102(43):15545-15550

31. Shen-Orr SS, Gaujoux R (2013) Computational deconvolution: extracting cell type-specific information from heterogeneous samples. Curr Opin Immunol 25(5):571-578

32. Szklarczyk D, Franceschini A, Wyder S, Forslund K, Heller D, Huerta-Cepas J, Simonovic M, Roth A, Santos A, Tsafou KP, Kuhn M, Bork P, Jensen LJ, von Mering C (2015) STRING v10: protein-protein interaction networks, integrated over the tree of life. Nucleic Acids Res 43(Database issue), D447-52

33. Tian R, Xu Y, Dou WW, Zhang H (2018) Bioinformatics analysis of microarray data to explore the key genes involved in HSF4 mutation-induced cataract. Int J Ophthalmol 11(6):910-917

34. Shannon P, Markiel A, Ozier O, Baliga NS, Wang JT, Ramage D, Amin N, Schwikowski B, Ideker T (2003) Cytoscape: a software environment for integrated models of biomolecular interaction networks. Genome Res 13(11):2498-2504

35. Chin CH, Chen SH, Wu HH, Ho CW, Ko MT, Lin CY (2014) cytoHubba: identifying hub objects and sub-networks from complex interactome. BMC Syst Biol 8(Suppl 4):S11

36. He X, Zhang $\mathrm{J}$ (2006) Why do hubs tend to be essential in protein networks? PLoS Genet 2(6):e88

37. Franzoni MS, Brandi A, de Oliveira Matos Prado JK, Elias F, Dalmolin F, de Faria LP, Prado MCM, Leis-Filho AF, Fonseca-Alves CE (2019) Tumor-infiltrating CD4(+) and CD8(+) lymphocytes and macrophages are associated with prognostic factors in triplenegative canine mammary complex type carcinoma. Res Vet Sci 126:29-36
38. Matoba T, Imai M, Ohkura N, Kawakita D, Ijichi K, Toyama T, Morita A, Murakami S, Sakaguchi S, Yamazaki S (2019) Regulatory T cells expressing abundant CTLA-4 on the cell surface with a proliferative gene profile are key features of human head and neck cancer. Int J Cancer 144(11):2811-2822

39. Parodi S, Pistoia V, Muselli M (2008) Not proper ROC curves as new tool for the analysis of differentially expressed genes in microarray experiments. BMC Bioinformatics 9:410

40. Li R, Chen C, Zhu S, Wang X, Yang Y, Shi W, Chen S, Wang C, Yan L, Shi J (2019) CGA-N9, an antimicrobial peptide derived from chromogranin A: direct cell penetration of and endocytosis by Candida tropicalis. Biochem J 476(3):483-497

41. Ghatalia P, Gordetsky J, Kuo F, Dulaimi E, Cai KQ, Devarajan K, Bae S, Naik G, Chan TA, Uzzo R, Hakimi AA, Sonpavde G, Plimack E (2019) Prognostic impact of immune gene expression signature and tumor infiltrating immune cells in localized clear cell renal cell carcinoma. J Immunother Cancer 7(1):139

42. Reyes D, Salazar L, Espinoza E, Pereda C, Castellon E, Valdevenito R, Huidobro C, Ines Becker M, Lladser A, Lopez MN, Salazar-Onfray F (2013) Tumour cell lysate-loaded dendritic cell vaccine induces biochemical and memory immune response in castration-resistant prostate cancer patients. Br J Cancer 109(6):1488-1497

43. Koizumi SI, Ishikawa H (2019) Transcriptional regulation of differentiation and functions of effector T regulatory cells. Cells 8(8)

44. Pruneri G, Vingiani A, Bagnardi V, Rotmensz N, De Rose A, Palazzo A, Colleoni AM, Goldhirsch A, Viale G (2016) Clinical validity of tumor-infiltrating lymphocytes analysis in patients with triple-negative breast cancer. Ann Oncol 27(2):249-256

45. Qiu L, Zhou Y, Yu Q, Zheng S, Wang Z, Huang Q (2018) Elevated levels of follicular $\mathrm{T}$ helper cells and their association with therapeutic effects in patients with chronic lymphocytic leukaemia. Immunol Lett 197:15-28

46. Liao R, Sun J, Wu H, Yi Y, Wang JX, He HW, Cai XY, Zhou J, Cheng YF, Fan J, Qiu SJ (2013) High expression of IL-17 and IL$17 \mathrm{RE}$ associate with poor prognosis of hepatocellular carcinoma. J Exp Clin Cancer Res 32:3

47. Jimbo H, Nagai H, Fujiwara S, Shimoura N, Nishigori C (2019) Fas-FasL interaction in cytotoxic T cell-mediated vitiligo: The role of lesional expression of tumor necrosis factor-alpha and interferon-gamma in Fas-mediated melanocyte apoptosis. Exp Dermatol 29(1):61-70

48. Fluhr H, Krenzer S, Stein GM, Stork B, Deperschmidt M, Wallwiener D, Wesselborg S, Zygmunt M, Licht P (2007) Interferongamma and tumor necrosis factor-alpha sensitize primarily resistant human endometrial stromal cells to Fas-mediated apoptosis. J Cell Sci 120(Pt 23):4126-4133

49. Quirk SM, Porter DA, Huber SC, Cowan RG (1998) Potentiation of Fas-mediated apoptosis of murine granulosa cells by interferongamma, tumor necrosis factor-alpha, and cycloheximide. Endocrinology 139(12):4860-4869

50. Jimbo H, Nagai H, Fujiwara S, Shimoura N, Nishigori C (2020) Fas-FasL interaction in cytotoxic $\mathrm{T}$ cell-mediated vitiligo: the role of lesional expression of tumor necrosis factor-alpha and interferon-gamma in Fas-mediated melanocyte apoptosis. Exp Dermatol 29(1):61-70

51. Williams JA, Zhang J, Jeon H, Nitta T, Ohigashi I, Klug D, Kruhlak MJ, Choudhury B, Sharrow SO, Granger L, Adams A, Eckhaus MA, Jenkinson SR, Richie ER, Gress RE, Takahama Y, Hodes RJ (2014) Thymic medullary epithelium and thymocyte self-tolerance require cooperation between CD28CD80/86 and CD40-CD40L costimulatory pathways. J Immunol 192(2):630-640

52. Brunner-Weinzierl MC, Rudd CE (2018) CTLA-4 and PD-1 control of T-Cell motility and migration: implications for tumor immunotherapy. Front Immunol 9:2737 
53. Singh R, Gupta P, Kloecker GH, Singh S, Lillard JW Jr (2014) Expression and clinical significance of CXCR5/CXCL13 in human nonsmall cell lung carcinoma. Int J Oncol 45(6):2232-2240

54. Zhang S, Kohli K, Black RG, Yao L, Spadinger SM, He Q, Pillarisetty VG, Cranmer LD, Van Tine BA, Yee C, Pierce RH, Riddell SR, Jones RL, Pollack SM (2019) Systemic interferon-gamma increases MHC class I expression and T-cell infiltration in cold tumors: results of a Phase 0 Clinical Trial. Cancer Immunol Res 7(8):1237-1243

55. Sanaei MJ, Salimzadeh L, Bagheri N (2019) Crosstalk between myeloid-derived suppressor cells and the immune system in prostate cancer: MDSCs and immune system in Prostate cancer. J Leukoc Biol 107(1):43-56

56. Cimino-Mathews A, Ye X, Meeker A, Argani P, Emens LA (2013) Metastatic triple-negative breast cancers at first relapse have fewer tumor-infiltrating lymphocytes than their matched primary breast tumors: a pilot study. Hum Pathol 44(10):2055-2063

57. Sami E, Paul BT, Koziol JA, ElShamy WM (2020) The immunosuppressive microenvironment in BRCA1-IRIS-overexpressing
TNBC tumors is induced by bidirectional interaction with TumorAssociated Macrophages. Cancer Res 80(5):1102-1117

58. Airoldi I, Cocco C, Morandi F, Prigione I, Pistoia V (2008) CXCR5 may be involved in the attraction of human metastatic neuroblastoma cells to the bone marrow. Cancer Immunol Immunother 57(4):541-548

59. Chen X, Takemoto Y, Deng H, Middelhoff M, Friedman RA, Chu TH, Churchill MJ, Ma Y, Nagar KK, Tailor YH, Mukherjee S, Wang TC (2017) Histidine decarboxylase (HDC)-expressing granulocytic myeloid cells induce and recruit Foxp3(+) regulatory T cells in murine colon cancer. Oncoimmunology 6(3):e1290034

60. Hussain M, Adah D, Tariq M, Lu Y, Zhang J, Liu J (2019) CXCL13/CXCR5 signaling axis in cancer. Life Sci 227:175-186

Publisher's Note Springer Nature remains neutral with regard to jurisdictional claims in published maps and institutional affiliations. 